\title{
Laminar-Turbulent Transition of a Low Reynolds Number Rigid or Flexible Airfoil
}

\author{
Yongsheng Lian* and Wei Shyy* \\ University of Michigan, Ann Arbor, Michigan 48109
}

DOI: $\underline{10.2514 / 1.25812}$

\begin{abstract}
Laminar-turbulent transition can affect the aerodynamic performance of low Reynolds number flyers, such as micro air vehicles that operate at the Reynolds number of $10^{4}-10^{5}$. To gain better understanding of the fluid physics and the associated aerodynamics characteristics, we coupled a Navier-Stokes solver, the $e^{N}$ transition model, and a Reynolds-averaged two-equation closure to study the low Reynolds number flow characterized with the laminar separation bubble and transition. A new intermittency function suitable for low Reynolds number transitional flow incurred by laminar separation is proposed and tested. With the method, we investigate the performance of a rigid airfoil and a flexible airfoil, mounted with a flexible membrane structure on the upper surface, using SD7003 as the configuration. Good agreement is obtained between the prediction and experimental measurements regarding the transition location, aerodynamic coefficients, and overall flow structures. We also examine the impact of gust on the transition process and airfoil performance. We further investigate the effect of the flexible surface on the transition. We find that the self-excited flexible surface vibration affects the separation and transition positions; however, the time-averaged lift and drag coefficients are close to those of the rigid airfoil.
\end{abstract}

\section{Nomenclature}

$C_{D}=$ drag coefficient

$C_{D f}=$ friction drag coefficient

$C_{L}=$ lift coefficient

$c=$ chord length

$H=$ shape factor, $\delta^{*} / \theta$

$k=$ turbulence kinetic energy

$N=$ critical factor in the transition model

$R e_{\theta}=$ Reynolds number based on the boundary-layer momentum thickness, $\rho u_{e} \theta / \mu$

$T i=$ turbulence intensity

$U_{e}=$ spatial velocity at the boundary-layer edge

$U_{0}=$ freestream velocity

$u_{\tau}=$ friction velocity

$\delta=$ boundary-layer thickness

$\delta^{*}=$ boundary-layer displacement thickness

$\theta=$ momentum thickness

$\mu=$ viscosity

$v_{t}=$ kinematic eddy viscosity

$\tau=$ nondimensionalized time, $t c / U$

$\omega=$ specific dissipation rate

$\omega_{g} \quad=$ gust frequency

\section{Introduction}

M ICRO air vehicles (MAVs), which are referred to as flight machines with a maximum dimension of $15 \mathrm{~cm}$ or less and an operating speed around $10 \mathrm{~m} / \mathrm{s}$, have attracted increasing attention because of their broad applications and the challenging research topics involved. In the design of MAVs, three distinct types of configurations were explored: fixed wings [1,2], flapping wings $[3,4]$, and rotary wings. For MAVs with a maximum linear dimension in the range between 10 and $15 \mathrm{~cm}$, fixed wings are

Presented as Paper 3051 at the 36th AIAA Fluid Dynamics Conference and Exhibit, San Francisco, CA, 5-8 June 2006; received 12 June 2006; revision received 7 February 2007; accepted for publication 24 February 2007. Copyright ( 2007 by Lian and Shyy. Published by the American Institute of Aeronautics and Astronautics, Inc., with permission. Copies of this paper may be made for personal or internal use, on condition that the copier pay the $\$ 10.00$ per-copy fee to the Copyright Clearance Center, Inc., 222 Rosewood Drive, Danvers, MA 01923; include the code 0001-1452/07 \$10.00 in correspondence with the CCC.

${ }^{*}$ Department of Aerospace Engineering. commonly adopted because they are simple in concept and easy to implement. Figure 1 shows the design of a 15-cm MAV featuring a flexible surface. The flexible-wing concept was discussed by Shyy et al. [5] and Lian et al. [6]. One advantage of the flexible wing is that it can facilitate passive shape adaptation, resulting in delayed stall. It was experimentally shown that under modest angles of attack, both rigid and membrane wings demonstrate similar lift characteristics [7]. However, the membrane wings stall at substantially higher angles of attack. For example, typical rigid wings for MAVs have stall angles between 12 and 15 deg, whereas flexible wings, which reduce their effective angle of attack due to the surface deformation [8], have stall angles between 30 and $45 \mathrm{deg}$.

A fixed wing, as a miniature of a large airplane wing, has deteriorative performance when its operating Reynolds number drops below $10^{5}$. Under such low Reynolds number conditions, the boundary layer at the onset of the pressure rise may still be laminar, and thus it is unable to resist substantial adverse pressure gradients and the flow separates. Under certain circumstances, the separated flow experiences laminar-turbulent transition and reattaches to form a laminar separation bubble (LSB). The laminar separation and the phenomena followed largely determine the MAV's aerodynamic performance. For this reason, fixed-wing research focuses on the low Reynolds number aerodynamics, including the laminar separation bubble and the laminar-turbulent transition.

Ever since the first observation by Jones [9], LSBs have been extensively investigated by numerous researchers, as reviewed by Young and Horton [10]. Over a low Reynolds number airfoil, if the freestream turbulence intensity is low, the flow starts as laminar; before transition, the laminar boundary layer separates due to the adverse pressure gradient aft of the velocity peak. The separated flow quickly undergoes transition and becomes turbulent. Depending on parameters such as the local Reynolds number, pressure gradient, surface roughness, and freestream turbulence intensity, the turbulent free shear layer may entrain enough high momentum fluid to reattach as a turbulent boundary layer behind a laminar separation bubble. Based on its size, the LSB can be categorized as either a short bubble or a long bubble [11]. A short bubble covers a small portion of the airfoil surface and plays an insignificant rule in modifying the velocity and pressure distributions, and a long bubble covers a considerable portion of the surface and significantly changes the inviscous pressure distribution and velocity peak. The presence of a bubble, especially a long one, leads to substantial change in the effective airfoil shape, causing the decrease of lift and increase of drag and, consequently, poor power efficiency [5]. 


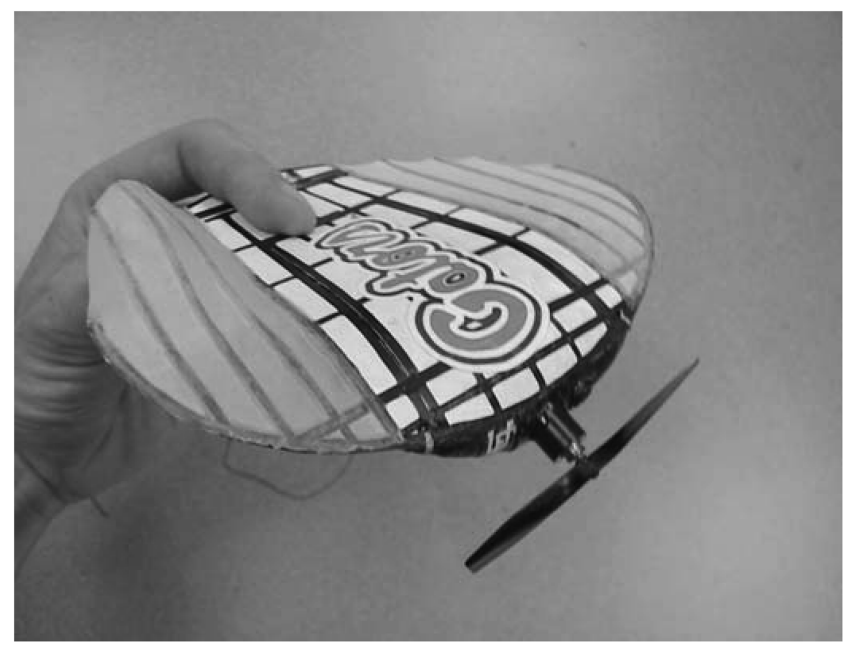

Fig. 1 MAV designs with fixed wing at the University of Florida (Ifju et al. [2]).

Because the onset of transition is affected by a wide spectrum of disturbance such as pressure gradient, wall roughness, freestream turbulence, acoustic noise, wall heating or cooling, wall suction or blowing, etc., a comprehensive transition model considering all these factors is not yet available. Even if we limit our focus on freestream turbulence, it is still a challenge to give an accurate mathematical description. In the general area of transitional flow study, approaches of transition prediction range from simple empirical methods through those based on parallel and linear stability theories such as the $e^{N}$ method $[12,13]$, to linear or nonlinear parabolized stability equations (PSE), to more comprehensive approaches such as direct numerical simulation (DNS) methods.

Most of the empirical methods are devised based on collective experimental measurements. For example, Roberts [14], Davis et al. [15], and Volino and Bohl [16] proposed models that estimate the transition length, typically based on the turbulence level on the boundary-layer edge at the separation point; Mayle [17], Praisner and Clark [18], and Roberts and Yaras [19] put forth models that predict the transition length using the local Reynolds number based on the momentum thickness. These models tend to oversimplify the downstream factors. For the attached flow, Wazzen et al. [20] proposed a model based on the shape factor. His model gives a unified correlation between the transition point and the Reynolds number for a variety of problems. For a separated flow, however, there is no similar model available.

There are other approaches based on linear stability analysis and boundary-layer theory. Among them, the $e^{N}$ method was adopted by multiple researchers $[12,13,21-23]$. The $e^{N}$ method solves the OrrSommerfeld equation to evaluate the local growth rate of unstable waves based on the velocity and temperature profiles over the body. Transition occurs when the amplification of the most unstable Tollmien-Schlichting (TS) wave reaches a certain value.

More sophisticate approaches were also proposed. For example, Holloway et al. [24] used the unsteady Reynolds-averaged NavierStokes model (URANS) to study the flow separation over a blunt body for the Reynolds number range between $10^{4}$ and $10^{7}$. Edwards et al. [25] developed a unified one-equation model by blending an eddy-viscosity-transport equation [26] with the standard SpalartAllmaras one-equation turbulence model [27]. Wilcox [28] proposed a low Reynolds number $k-\omega$ turbulence model to predict transition. Steelant and Dick [29], Suzen and Huang [30], and Suzen et al. [31] incorporated the concept of the intermittency factor to model the transitional flows. This kind of approach is achieved either by using the conditioned Navier-Stokes equations or by using the intermittency factor. In all cases, the intermittency factor is solved from a transport equation, which is typically based on empirical correlations. More important, the onset of transition is determined by empirical correlations. Zheng et al. [32] presented another approach by coupling Wilcox's low Reynolds number $k-\omega$ model with a sensor technique. The sensor, which is a function of streamline curvature, is introduced to detect separation and trigger transition. The rationale is to increase the eddy viscosity in the circulation zone. Therefore, the result is sensitive to the topology of the separation bubble. Our tests (not shown here), based on the SD7003 airfoil [33], show that this method works well for short separation bubbles but underpredicts the length of long bubbles.

The concept of coupling the RANS solver and the $e^{N}$ method to predict transition was practiced by Radespiel et al. [34] and Stock and Haase [35]. More recent application can be found in the work of Yuan et al. [36]. Even though in practice the $e^{N}$ method was extended to study the three-dimensional flow [37], the physical meaning of the envelope method is not clear.

The large-eddy simulation (LES) [38] and direct numerical simulation are also being employed to study laminar-turbulent transition. For example, Yang and Voke [39] investigated boundarylayer separation and transition employing LES. Yuan et al. [36] studied transition over a low Reynolds number airfoil using L $\overline{\mathrm{ES}}$. However, given the complexity of the transition physics and the need for accounting for complex geometry in practice, the $e^{N}$ method is expected to remain a practical approach for engineering applications.

In the present work, we simulate the transitional flow by coupling an incompressible RANS solver with the $e^{N}$ method. The $e^{N}$ method is based on the work by Drela and Giles [23]. This paper is structured as follows: first, we present the geometric description of the chosen airfoil and some recent experimental work related to the airfoil; second, we introduce the major modeling and numerical approaches employed in this work; and third, we present the numerical results and discuss the outcome. In the numerical result section, we first validate our transitional model against available experimental data, and then we examine the effects of angle of attack, freestream turbulence intensity, Reynolds number, and gust on the transition behavior and the airfoil performance. Last, we study the transitional flow over a flexible airfoil.

\section{Experimental Study of SD7003 Airfoil}

We use the SD7003 airfoil [33] in the present work. The airfoil has a maximum thickness of $8.5 \%$ and a maximum camber of $1.48 \%$. The geometry is shown in Fig. 2. The SD7003 airfoil has received substantial experimental investigations because it exhibits a long, stable LSB over a broad range of angles of attack at Reynolds numbers below $10^{5}$ [40]. Three groups (Hanff [41] at the Institute for Aerospace Research, Radespiel et al. [42] at the Technical University of Braunschweig, and $\mathrm{Ol}$ et al. [40] at the U.S. Air Force Research Laboratory) used the SD7003 airfoil to experimentally study LSB and transition. A detailed comparison of instruments and experimental results can be found in the work of $\mathrm{Ol}$ et al. In Table 1, we summarize the tunnel types and particle image velocimetry (PIV) resolutions. Among the three, the work by Radespiel et al. has the highest resolution.

For the work of Hanff [41], the measurements were taken at a Reynolds number of $6 \times 10^{4}$ and angle of attack of 4 deg; Radespiel et al. [42] and $\mathrm{Ol}$ et al. [40] extended their measurements to other angles of attack. The locations of separation, transition onset, timeaveraged reattachment, and maximum bubble height at the angle of attack of 4 deg are listed in Table 2 , along with the estimated facility turbulence intensity.

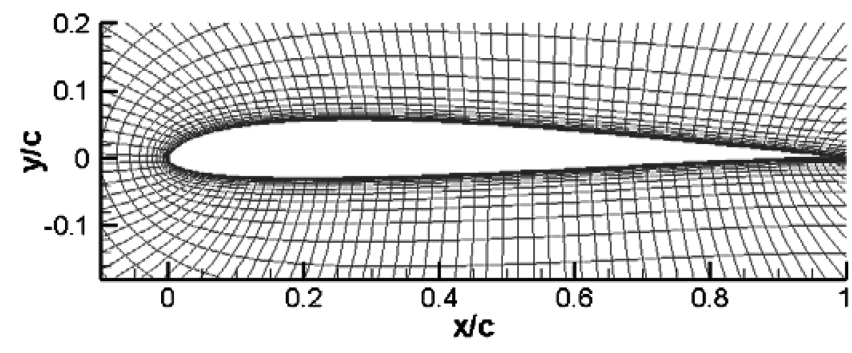

Fig. 2 SD7003 airfoil with $8.5 \%$ thickness and $1.4 \%$ camber. 
Table 1 Comparison of PIV resolution for the three data sets [40]

\begin{tabular}{lccc}
\hline \hline Group & Tunnel type & $\begin{array}{c}\text { Window width, } \\
\text { pixels } \\
\% \text { chord }\end{array}$ & $\begin{array}{c}\text { Vector spacing, } \\
\text { pixels } \\
\% \text { chord }\end{array}$ \\
\hline Hanff [41] & Tow tank & $16(0.46 \%)$ & $4(0.12 \%)$ \\
Radespiel et al. [녀] & Wind tunnel & $16(0.16 \%)$ & $8(0.085 \%)$ \\
Radespiel et al. [42] & Water tunnel & $32(0.32 \%)$ & $8(0.085 \%)$ \\
Ol et al. [40] & Water tunnel & $32(0.44 \%)$ & $16(0.22 \%)$ \\
\hline \hline
\end{tabular}

Regardless of the differences in the freestream turbulence, the measured maximum bubble heights agree well with each other. The separation, transition, and reattachment points agree well between the measurements by Hanff [41] and Radespiel et al. [42], whereas Ol et al. [40] predicted that the flow separates and reattaches further upstream. The reason, as explained by $\mathrm{Ol}$ et al., is that in their experiment, the true angle of attack may be slightly larger than the correct value. Nevertheless, the measured lift coefficient by $\mathrm{Ol}$ et al. is in line with the measurement by Selig et al. [33] and XFOIL prediction at modest angles of attack.

\section{Numerical Methods}

\section{Reynolds-Averaged Navier-Stokes Solver}

We simulate the transitional flow by solving the incompressible Navier-Stokes equations coupled with a transition model. The equations are written in three-dimensional curvilinear coordinates and are solved with a pressure-based algorithm, generalizing from the original semi-implicit method for pressure-linked equations (SIMPLE) $[43,44]$. We discretize the convection terms with the second-order upwind scheme and discretize the diffusion terms with the second-order central-difference scheme. The time integration is performed with an implicit three-point backward scheme for better handling of accuracy and strict time-step constraint imposed by the extremely fine grid resolution. We use Wilcox's $k-\omega$ turbulence model [45] as the turbulence closure. For clarity, the turbulence model is written in Cartesian coordinates, as follows:

$$
\begin{aligned}
& \frac{\partial k}{\partial t}+\frac{\partial\left(u_{j} k\right)}{\partial x_{j}}=\frac{\tau_{i, j}}{\rho} \frac{\partial u_{i}}{\partial x_{j}}-\beta^{*} \omega k+\frac{\partial}{\partial x_{j}}\left[\left(v+\sigma^{*} v_{T}\right) \frac{\partial k}{\partial x_{j}}\right] \\
& \frac{\partial(\rho \omega)}{\partial t}+\frac{\partial\left(u_{j} \omega\right)}{\partial x_{j}}=\frac{\alpha \omega}{k} \frac{\tau_{i, j}}{\rho} \frac{\partial u_{i}}{\partial x_{j}}-\beta \omega^{2} \frac{\partial}{\partial x_{j}}\left[\left(v+\sigma v_{T}\right) \frac{\partial \omega}{\partial x_{j}}\right]
\end{aligned}
$$

where

$$
\begin{gathered}
\nu_{T}=\alpha^{*} k / \omega, \quad \tau_{i, j}=2 \rho v_{T} S_{i, j}-2 / 3 \rho k \delta_{i, j} \\
S_{i j}=\frac{1}{2}\left(\frac{\partial u_{i}}{\partial x_{j}}+\frac{\partial u_{j}}{\partial x_{i}}\right) \\
\alpha^{*}=\frac{\alpha_{0}^{*}+R e_{T} / R_{k}}{1+R e_{T} / R_{k}}, \quad \alpha=\frac{13}{25} \frac{\alpha_{0}+R e_{T} / R_{\omega}}{1+R e_{T} / R_{\omega}} \frac{1}{\alpha^{*}} \\
\beta^{*}=\frac{9}{100} \frac{4 / 15+\left(R e_{T}+R_{\beta}\right)^{4}}{1+\left(R e_{T}+R_{\beta}\right)^{4}} \\
\operatorname{Re}_{T}=\frac{k}{\omega \nu}, \quad \beta=\frac{9}{125}, \quad \sigma^{*}=\sigma=\frac{1}{2} \\
\alpha_{0}^{*}=\frac{1}{3} \beta, \quad \alpha_{0}=\frac{1}{9}
\end{gathered}
$$

$$
R_{\beta}=8, \quad R_{k}=6, \quad R_{\omega}=2.95
$$

In the simulations, the value of turbulence kinetic energy at the freestream is set based on the experimental data. Because there is no direct measurement for the dissipation rate, we assign a value of $\omega$ so that the resulting turbulence kinetic eddy viscosity of $v_{t}=k / \omega$ is much smaller than the laminar kinetic viscosity. On the wall surface, the kinetic energy is set to zero, and the dissipation rate is set as follows:

$$
\omega=u_{\tau}^{2} S_{R} / v
$$

where we set $S_{R}$ to 500 to simulate the smooth wall.

\section{Transition Model}

The $e^{N}$ method is based on linear stability analysis and it states that transition occurs when the most unstable TS wave in the boundary layer was amplified by a factor of $e^{N}$, where $N$ is defined as follows:

$$
N=\max _{\omega} \tilde{n}\left(x_{t} ; \omega\right) \quad \tilde{n}(x ; \omega)=-\int_{x_{0}}^{x} \alpha_{i}(\omega) \mathrm{d} x
$$

where $\omega$ is the frequency, $x_{0}(\omega)$ is the onset location of instability, $-\alpha_{i}$ is the spatial growth rate of the TS wave, and $n(x ; \ldots)$ describes the amplitude growth of the disturbance along the chord of the airfoil. Given a velocity profile, the local disturbance growth rate can be determined by solving the Orr-Sommerfeld eigenvalue equations. Then the amplification factor is calculated by integrating the growth rate, usually the spatial growth rate, starting from the point of neutral stability. For incompressible flow, the integrated growth rate can be approximated by straight lines [46], as follows:

$$
\tilde{n}=\frac{\mathrm{d} \tilde{n}}{\mathrm{~d} R e_{\theta}}(H)\left[R e_{\theta}-R e_{\theta_{0}}(H)\right]
$$

where $R e_{\theta}$ is the Reynolds number based on the boundary-layer momentum thickness, and $H$ is the boundary-layer shape factor. With this approach, we can approximate the amplification factor with a relatively good accuracy without resorting to solving the eigenvalue equations. This approach is also adopted by Drela and Giles [23]. For similar Blasius flow, the amplification factor $\tilde{n}$ is determined by the following empirical formula:

$$
\frac{\mathrm{d} \tilde{n}}{\mathrm{~d} \operatorname{Re}_{\theta}}=0.01\left\{[2.4 H-3.7+2.5 \tanh (1.5 H-4.65)]^{2}+0.25\right\}^{1 / 2}
$$

\begin{tabular}{|c|c|c|c|c|c|}
\hline Group & $\begin{array}{c}\text { Freestream turbulence } \\
\text { level } T_{i}, \%\end{array}$ & $\begin{array}{c}\text { Separation position } \\
x_{s} / c\end{array}$ & $\begin{array}{c}\text { Transition position } \\
x_{t} / c\end{array}$ & $\begin{array}{l}\text { Reattachment position } \\
\qquad x_{r} / c\end{array}$ & $\begin{array}{c}\text { Max bubble height, } \\
h_{b} / c\end{array}$ \\
\hline Hanff $[41]$ & 0.0 & 0.33 & 0.57 & 0.63 & 0.027 \\
\hline Radespiel et al. [42] & 0.08 & 0.30 & 0.53 & 0.62 & 0.028 \\
\hline
\end{tabular}

For nonsimilar flow, based on the properties of the Falkner-Skan profile family, the amplification factor with respect to the spatial coordinate $\xi$ is expressed as

$$
\frac{\mathrm{d} \tilde{n}}{\mathrm{~d} \xi}=\frac{\mathrm{d} \tilde{n}}{\mathrm{~d} \operatorname{Re}_{\theta}} \frac{1}{2}\left(\frac{\xi}{u_{e}} \frac{\mathrm{d} u_{e}}{\mathrm{~d} \xi}+1\right) \frac{\rho_{e} u_{e} \theta^{2}}{u_{e} \xi} \frac{1}{\theta}
$$

An explicit expression for the integrated amplification factor then becomes

$$
\tilde{n}(\xi)=\int_{\xi_{0}}^{\xi} \frac{\mathrm{d} \tilde{n}}{\mathrm{~d} \xi} \mathrm{d} \xi
$$

where $\xi_{0}$ is the point at which $R e_{\theta}=R e_{\theta_{0}}$, and the critical Reynolds numbers are expressed by the following empirical formulas:

Table 2 Measured SD7003 LSB properties at $R e=6 \times 10^{4}$ and 4-deg angle of attack 


$$
\begin{aligned}
& \log _{10} R e_{\theta_{0}}=\left(\frac{1.415}{H-1}-0.489\right) \tanh \left(\frac{20}{H-1}-12.9\right) \\
& +\frac{3.295}{H-1}+0.44
\end{aligned}
$$

The $\mathrm{e}^{N}$ method requires that the following assumptions be satisfied:

1) The initial disturbance is infinitesimally small.

2) The laminar boundary layer is thin and gradually grows in the streamwise direction.

Although the second assumption seems stringent to the LSB study, the DNS simulation shows that the assumption of parallel flow needed for the linear stability computations is largely satisfied for a broad range of LSBs [47,48].

Evaluating the amplification factor requires the extraction of boundary-layer parameters from the Navier-Stokes solution. For flow over a curved object, the boundary-layer edge can be detected by using the Bernoulli equation [36]. Because pressure can be assumed constant normal to the wall within the boundary layer, the boundary-layer edge velocity for incompressible flow can be calculated as

$$
U_{e}=\sqrt{U_{0}^{2}-2 \frac{p_{0}}{\rho}\left(\frac{p_{w}}{p_{0}}-1\right)}
$$

where the subscript 0 indicates freestream values and $p_{w}$ is the pressure on the wall. The boundary-layer edge is then defined as the point at which the local velocity $U$ is equal to $0.99 U_{e}$. Similar to the experience of other reported studies, we notice that sometimes $U$ is never reached [19]. Under that situation, the point with the maximum streamwise velocity component is taken as the boundary-layer edge instead. Once the boundary-layer edge is located, other boundary parameters can be defined. For example, the displacement thickness and the momentum thickness are calculated in the following way:

$$
\delta^{*}=\int_{0}^{\delta}\left(1-\frac{U}{U_{e}}\right) \mathrm{d} \eta, \quad \theta=\int_{0}^{\delta} \frac{U}{U_{e}}\left(1-\frac{U}{U_{e}}\right) \mathrm{d} \eta
$$

To account for the smooth rise of turbulence from laminar flow, a variety of intermittency distribution functions are proposed [49]. For example, Cebeci [22] improved the intermittency distribution function of Chen and Thyson [50] to compass a low Reynolds number range from $2.4 \times 10^{5}$ to $2 \times 10^{6}$ with a laminar separation bubble. However, no model is available when the Reynolds number is lower than $10^{5}$. We deduce that for separation-caused transition at such low Reynolds number conditions, the intermittency distribution is largely determined by the length from the separation point to the transition point. The shorter the length, the quicker the flow becomes turbulence. Also, previous work suggests that the flow property at the transition point will also be important. Based on the available experimental data and our simulation, we suggest the following model:

$$
\begin{aligned}
& \gamma \\
& = \begin{cases}1-\exp \left\{-\left[\exp \left(\frac{\max \left(H_{T}-2.21,0\right)}{20}\right)^{2}-1\right]\left(\frac{x-x_{T}}{x_{T}-x_{S}}\right) R e_{\theta T}\right\} & \left(x \geq x_{T}\right) \\
0 & \left(x<x_{T}\right)\end{cases}
\end{aligned}
$$

where $x_{T}$ is the transition onset position, $x_{S}$ is the separation position, $H_{T}$ is the shape factor at the transition onset, and $R e_{\theta T}$ is the Reynolds number based the momentum thickness at the onset point of transition.

In summary, the computation begins with solving the RANS equations. The $k-\omega$ turbulence model equations are solved without changing the effective viscosity, namely, $v_{T}=0$. The boundarylayer parameters are then extracted from the Navier-Stokes solution to evaluate the amplification factor. Once the threshold factor $N$ is reached, the flow becomes turbulent, the production terms are switched on, and the eddy viscosity is added to the effective viscosity. By using the intermittency factor, the RANS equations are coupled with the transition model in the following way:

$$
v_{T}= \begin{cases}0 & x \leq x_{T} \\ \gamma v_{T} & x>x_{T}\end{cases}
$$

The freestream intensity effect can be incorporated into the $\mathrm{e}^{N}$ method by the following correlation proposed by Mack [51]:

$$
N=-8.43-2.4 \ln \left(T_{i}\right), \quad 0.0007 \leq T_{i} \leq 0.0298
$$

Henkes and van Ingen [52] also proposed a similar formula. Due caution should be taken when those correlations are used. The freestream turbulence intensity itself is not sufficient to describe the disturbance. Information about the distribution across the frequency spectrum should also be considered. The so-called receptivity (i.e., how the initial disturbances within the boundary layer are related to the outside disturbances) is a critically important issue. Actually, we can only determine the $N$ factor if we know the "effective $T_{i}$," which can only be defined through a comparison of measured transition position with calculated amplification ratios [52]. Mack's [51] correlation is used throughout our work.

\section{Structural Model}

To simulate the flow over a flexible surface, such as that shown in Fig. 1, we need a structural solver to model the transient behavior of the flexible surface. A dynamic membrane model proposed by Lian et al. [53] is adopted here. In the model, the membrane material is assumed to obey the hyperelastic Moody-Rivlin model. For an initially isotropic membrane, Green and Adkins [54] showed that there exits a strain energy function $W$ that can be expressed as the following form:

$$
W=W\left(I_{1}, I_{2}, I_{3}\right)
$$

where $I_{1}, I_{2}$, and $I_{3}$ are the first, second, and third invariants of the Green deformation tensor. If the material is incompressible, namely, $I_{3}=1$, then the strain energy is a function of $I_{1}$ and $I_{2}$ only. The following linear form was found valuable in the study of such a membrane:

$$
W=c_{1}\left(I_{1}-3\right)+c_{2}\left(I_{2}-3\right)
$$

where $c_{1}$ and $c_{2}$ are the two material parameters. The Moody-Rivlin model is one of the most frequently employed hyperelastic models because of its mathematical simplicity and relatively good accuracy for reasonably large strains (less than 150\%) [55].

The finite element procedure is based on the principle of virtual work. A triangular element is employed. The system of governing equations for membrane responses under external load can be formulated as follows:

$$
\mathbf{M} \ddot{\boldsymbol{D}}(t)+\boldsymbol{F}^{\mathrm{int}}=\boldsymbol{F}^{\mathrm{ext}}
$$

where $\mathbf{M}$ is a positive definite mass matrix, which remains constant, $\boldsymbol{D}(t)$ represents the nodal displacement vector in global coordinates, $\ddot{\boldsymbol{D}}(t)$ is the nodal acceleration vector, $\boldsymbol{F}^{\text {int }}$ is the internal force, and $\boldsymbol{F}^{\text {ext }}$ is the external load. To integrate the system of Eqs. (20), we adopt the widely used implicit Newmark's family of methods [56].

The coupling between the fluid solver and the structural solver is achieved through exchanging information at the interface: the aerodynamic force is transferred from the fluid solver to the structural solver, whereas the surface deformation is transferred from the structural solver to the fluid solver. A detailed description of this approach is described by Lian and Shyy [8].

\section{Moving-Grid Technique}

The moving-grid technique adopted here is based on the spring analogue methods and master-slave concept. This approach maintains a point-matched grid-block interface while preserving grid quality and preventing potential grid crossover [57]. The 
Table 3 Grid-sensitivity analysis for $\alpha=4 \mathrm{deg}$ and $N=8$

\begin{tabular}{lllllcc}
\hline \hline Case & Grid size & $C_{L}$ & $C_{D}$ & $C_{D f}$ & $\begin{array}{c}\text { Separation position } \\
x_{s} / c\end{array}$ & $\begin{array}{c}\text { Transition position } \\
x_{T} / c\end{array}$ \\
\hline 1 & $220 \times 136$ & 0.55 & 0.024 & 0.010 & 0.20 & 0.47 \\
2 & $330 \times 136$ & 0.62 & 0.024 & 0.010 & 0.20 & 0.21 \\
3 & $640 \times 136$ & 0.61 & 0.023 & 0.011 & 0.21 & 0.48 \\
4 & $220 \times 190$ & 0.60 & 0.023 & 0.011 & 0.21 & 0.50 \\
5 & $330 \times 190$ & 0.61 & 0.023 & 0.011 & 0.21 & 0.48 \\
6 & $640 \times 190$ & 0.61 & 0.024 & 0.011 & \\
\hline \hline
\end{tabular}

following formula used by Visbal and Gaitonde [58] is adopted in our work:

$$
\dot{x}=\frac{3 x^{n+1}-4 x^{n}+x^{n-1}}{2 \Delta t}
$$

where the superscripts $n+1, n$, and $n-1$ refer to the current time instant and the past two consecutive time instants, respectively. The Jacobian matrix needs to be updated by enforcing the geometric conservation law [59].

\section{Results and Discussion}

Our numerical simulations follow the experimental setup of $\mathrm{Ol}$ et al. [40]. The fluid has a density of $1000 \mathrm{~kg} / \mathrm{m}^{3}$ and viscosity of $0.001 \overline{\mathrm{kg}} / \mathrm{m} \cdot \mathrm{s}$. The freestream velocity is $0.3 \mathrm{~m} / \mathrm{s}$. Based on the freestream velocity and airfoil chord length of $20 \mathrm{~cm}$, the Reynolds number is $6 \times 10^{4}$.

\section{Grid-Sensitivity Analysis}

To minimize the boundary condition effects, we set the outer boundary 25 chords away from the airfoil. Close to the wall, we strive to ensure that there are at least 30 grid points within the boundary layer, and in the turbulent region, we make the $y^{+}$of the first grid point less than 0.2 . During the sensitivity analysis, we find that at lower angles of attack, the aerodynamic coefficients have insignificant variations with respect to the change of the computational grid. At higher angles of attack, when the separation point moves toward the leading edge and the transition abruptly occurs within a short distance, the grid distribution exhibits a significant impact on the computed solution. Grid-sensitivity analysis at $\alpha=4 \mathrm{deg}$ is shown in Table 3 . The lift coefficient, except for case 1 , varies less than $2 \%$. The drag coefficient shows convergence with grid refinement. The friction drag coefficient is around 0.011 for all cases. Both the separation position and transition position also show convergence pattern. Similar conclusions are drawn for sensitivity analysis at higher angles of attack. Based on these tests, we choose the grid with $330 \times 190$ points for all computations reported next.

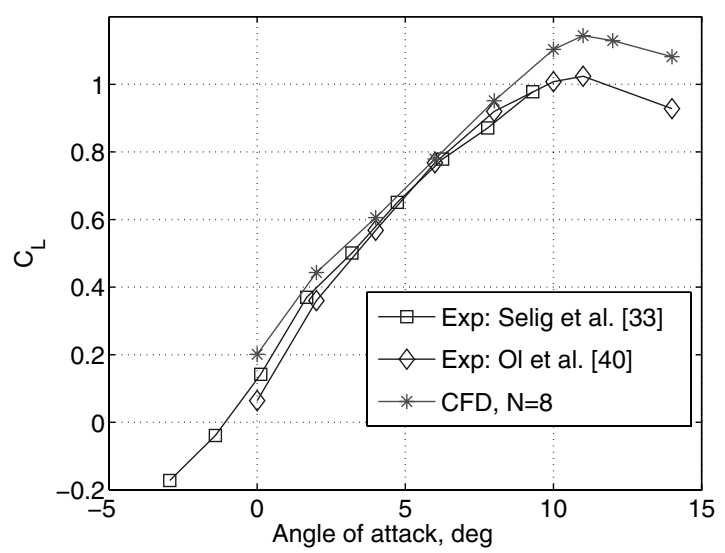

\section{Effect of Angle of Attack}

The lift and drag coefficients at different angles of attack are plotted in Fig. 3. Our computed results have good agreement with the experimental measurements at modest angles of attack. Both our simulation and the measurement by $\mathrm{Ol}$ et al. [40] predict that the maximum lift coefficient happens at $11 \mathrm{deg}$. Close to stall, our simulation overpredicts the lift coefficient.

At zero angle of attack, laminar separation occurs on the upper surface at about $77 \%$ chord position from the leading edge. Because the adverse pressure gradient is modest, the separated flow is able to reattach to the surface at $93 \%$ chord position and forms a thin laminar separation bubble (the maximum height is less than $1 \%$ of the chord length). However, the flow remains laminar in the entire domain. As the angle of attack increases, as illustrated in Fig. 4, the adverse pressure gradient aft of the point of suction peak becomes stronger and the separation point moves toward the leading edge. The stronger pressure gradient amplifies the disturbance in the separation zone and prompts transition. As the turbulence develops, the increased entrainment causes flow reattachment [60]. At an angle of attack of $2 \mathrm{deg}$, the separation position is at around $37 \%$ chord position and transition occurs at $75 \%$ chord position. A long laminar separation bubble forms. The plateau of the pressure distribution shown in Fig. 4a is characteristic of a laminar separation bubble. It is also noticed from Fig. $\underline{4 b}$ that the bubble length decreases with the increase of angle of attack.

The turbulent shear stress, which causes transport of momentum across the boundary layer, is responsible for the closure of the laminar separation bubble. Therefore, it will be helpful to investigate its distribution within the transition region. Radespiel et al. [42] measured the shear stress in the low-turbulence wind tunnel (LNB) and the water tunnel (WUB) at the Technical University of Braunschweig. The measurement at $\alpha=4 \mathrm{deg}$ is performed at the LNB. Figure 5 compares the experimental measurement, the numerical simūation by Radespiel et al., and our simulation. Radespiel et al. pointed out that due to the low freestream intensity in the experiment, a rather large critical $N$ factor is suitable for the case of $\alpha=4 \mathrm{deg}$. A critical factor of 10 is adopted, and Menter's [61] baseline turbulence model is used in their work. In our simulation, the critical $N$ factor is determined by the correlation previously shown in Eq. (17). Based on the measured turbulence intensity of

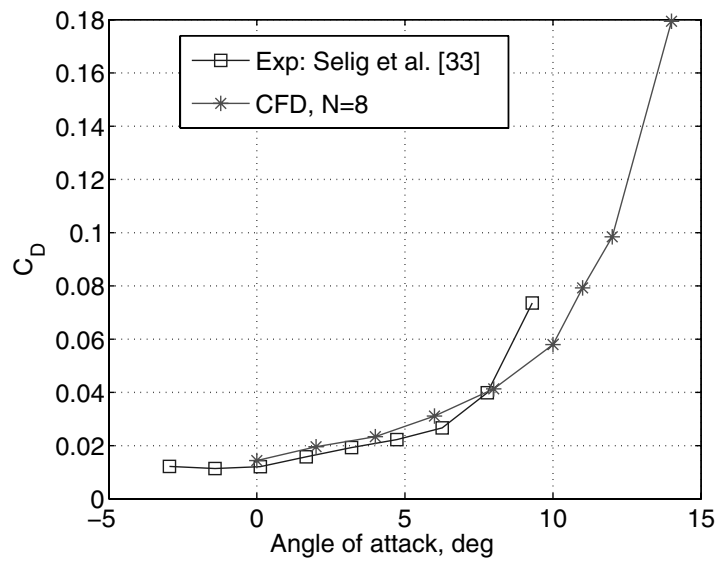

Fig. 3 Lift and drag coefficients vs angle of attack for SD7003 airfoil at $R e=6 \times 10^{4}$. 


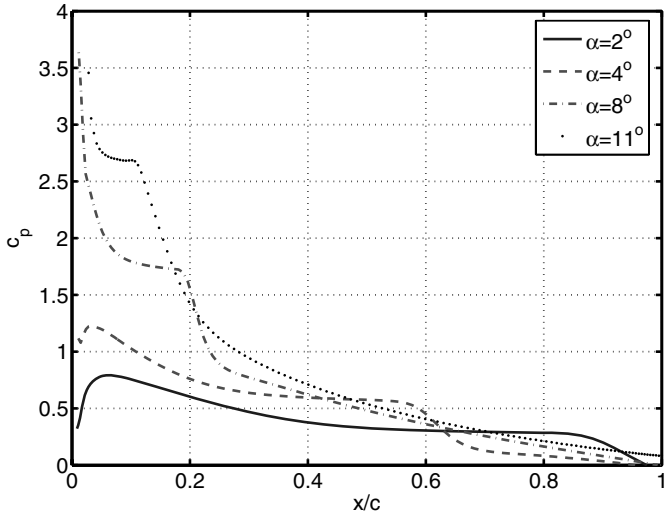

a)

7003 airfoll at $R e=6 \times 10$ )

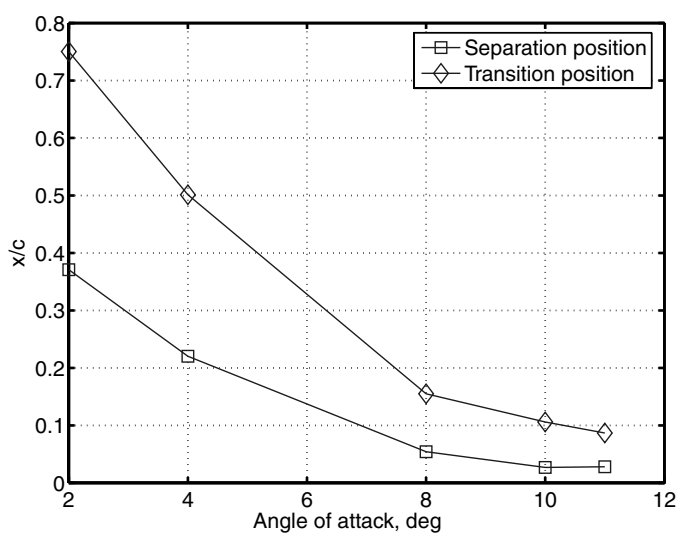

b)

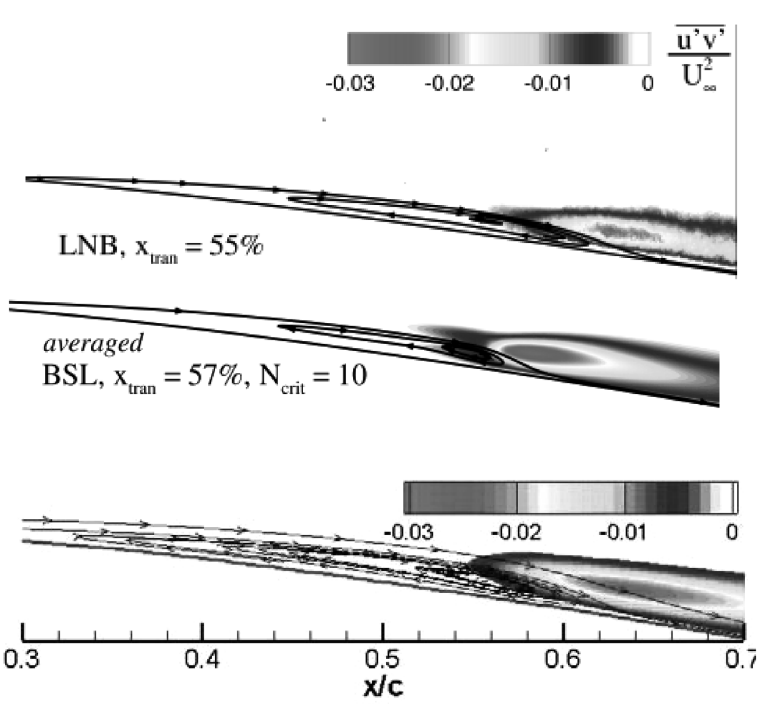

Fig. 5 Streamlines and turbulent shear stress for $\alpha=4 \mathrm{deg}$; top: experimental measurement by Radespiel et al. [42]; middle: numerical simulation by Radespiel et al. with $N=10$ (with permission from the authors); and bottom: present numerical simulation with $N=8$.

$0.08 \%$, the critical $N$ factor is set to eight. Our results show that the flow experiences transition at $50 \%$ of the chord position, whereas the experiment shows that transition occurs at $55 \%$ of the chord. It should be noted that in the experiment, the transition location is defined as the point at which the normalized Reynolds shear stress reaches $0.1 \%$ and demonstrates a clearly visible rise. The transition point in our simulation is defined as the point at which the most unstable TS wave has amplified by a factor of $e^{N}$. If using the normalized shear stress threshold $0.1 \%$ as the criteria, the transition point is at $56 \%$ of the chord, based on our simulation. Overall, as shown in Fig. 5, our simulation shows good agreement with the experimental results in terms of transition position, reattachment position, and vortex core position. However, our simulations have noticeably lower shear-stress magnitude than the experiment.

As the angle of attack increases, both the separation and transition positions move upstream and the bubble shrinks in size. The measurements at $\alpha=8$ and $11 \mathrm{deg}$ were performed in the water tunnel with a measured freestream turbulence intensity of $0.8 \%$. At $\alpha=8 \mathrm{deg}$, our simulation predicts that the flow goes though transition at $15 \%$ of the chord, which is close to the experiment measurement of $14 \%$. The bubble covers approximately $8 \%$ of the airfoil upper surface. The computational and experimental results for $\alpha=8$ deg are shown in Fig. 6 . With a critical factor of 8 , Radespiel et al. [42] predicted that transition took place at $16.5 \%$ of the chord . At the angle of attack of $11 \mathrm{deg}$, the airfoil is close to stall. The separated flow requires a greater pressure recovery in the laminar
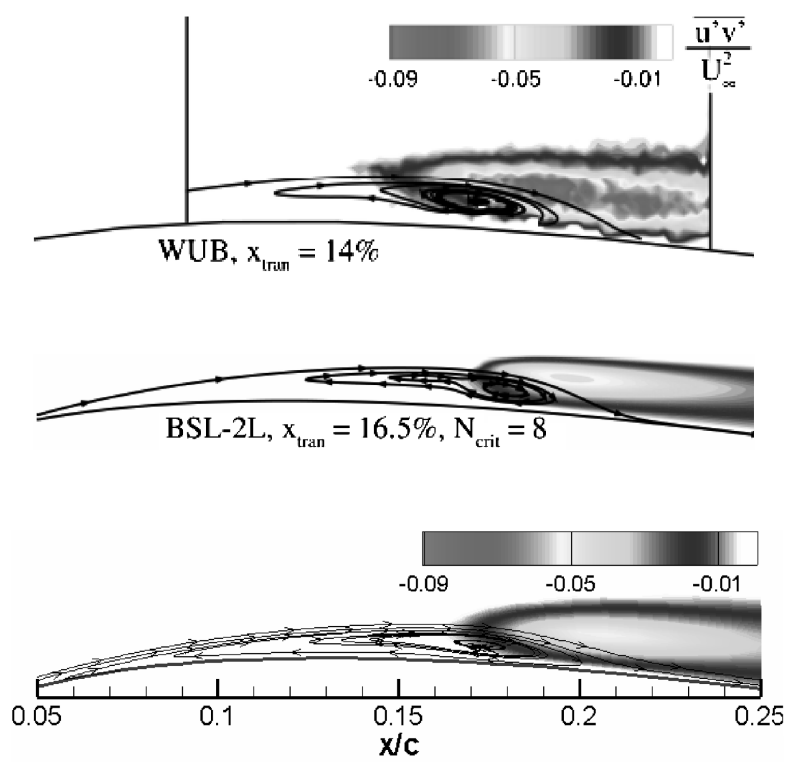

Fig. 6 Streamlines and turbulent shear stress for $\alpha=8 \mathrm{deg}$; top: experimental measurement by Radespiel et al. [42] with freestream turbulence intensity of $0.8 \%$; middle: numerical simulation by Radespiel et al. with $N=8$ (with permission from the authors); and bottom: present numerical simulation with $N=3$.

bubble for reattachment. Otherwise, the bubble will burst and become a long bubble. Our simulation shows that the flow separates at $5 \%$ of the chord, and the separated flow quickly reattaches after it experiences transition at $7.5 \%$ of the chord position, whereas the experiment showed that transition occurred at $8.3 \%$. This quick reattachment generally represents the transition-forcing mechanism [60]. Comparison shows that the computed Reynolds shear stress well matches the experiment measurement (Fig. 7). With the twolayer turbulence model of Menter [61] and a critical factor of 7, Radespiel et al. predicted that transition happened at $8.1 \%$ of the chord.

\section{Effect of Freestream Turbulence Intensity}

Five turbulence levels are chosen to evaluate their impact on the transition process. The critical $N$ factor is adjusted based on Eq. (17). The lift and drag coefficients are shown in Fig. 8 . At $\alpha=4 \mathrm{deg}$, there is no noticeable difference in the lift and drag coefficients among the five tested turbulence levels, even though it changes the pressure coefficient distribution, as shown in Fig. 9 .

At $\alpha=8 \mathrm{deg}$, there is a drastic decrease in the lift coefficient and increase in the drag coefficient when $T i$ decreases to $0.07 \%$. Analyzing the flow structure shows that the flow fails to reattach after 

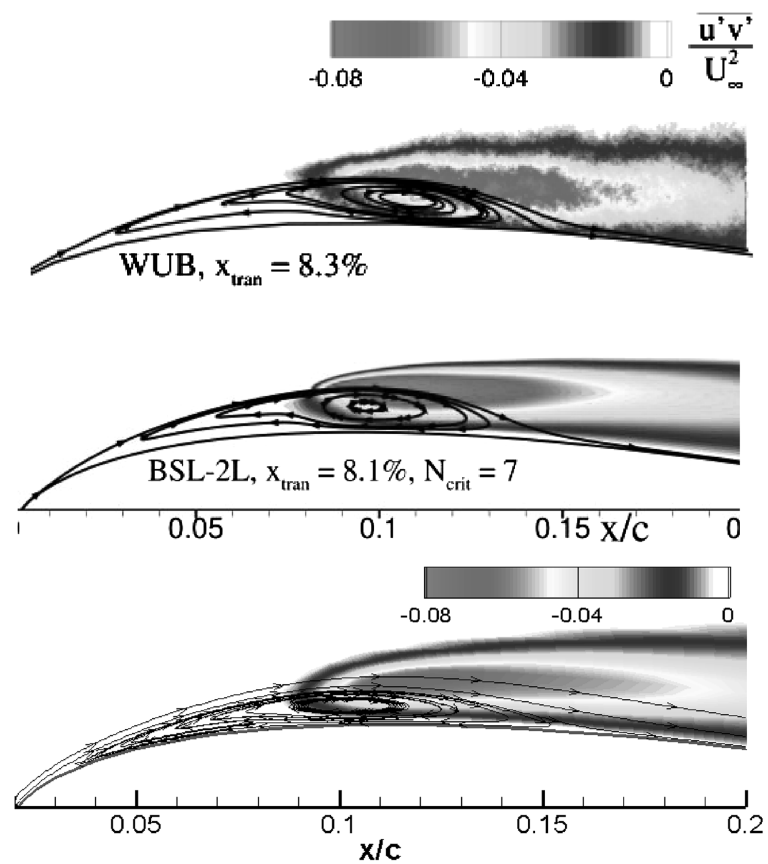

Fig. 7 Streamlines and turbulent shear stress for $\alpha=11 \mathrm{deg}$; top: experimental measurement by Radespiel et al. [42] with freestream turbulence intensity of $0.8 \%$; middle: numerical simulation by Radespiel et al. with $N=7$ (with permission from the authors); and bottom: present numerical simulation with $N=3$.

the initial separation. This burst separation bubble causes the lift coefficient to drop by $10 \%$ and the drag coefficient to increase by more than $150 \%$. Similar conclusion can be made for the case of $\alpha=11 \mathrm{deg}$.

It is clear from Fig. 10 that the LSB becomes thinner and shorter with the increase of the freestream turbulence level. From the same figure, we can also see that the shear stress decreases with the freestream turbulence level. Because of the viscous effect, the boundary layer and the LSB change the effective shape of the airfoil, which can be approximated by superimposing the viscous displacement thickness to the airfoil. As shown in Fig. 11, the flow "feels" a thicker airfoil due to the viscous effect. The flow with a higher freestream turbulence level feels a relatively thinner airfoil than the flow with a lower turbulence level. In their experimental work with a NACA 663-018 airfoil, O'Meara and Mueller [62] reported that higher turbulence intensity led to a shorter and thinner separation bubble and a higher suction peak. In their study, the bubble length is around $7 \%$ of the chord. For the long laminar bubble reported here, we observe that as the turbulence intensity increases, the bubble decreases in length and thickness. However, we do not find clear evidence that it can increase the suction peak (Fig. 9).

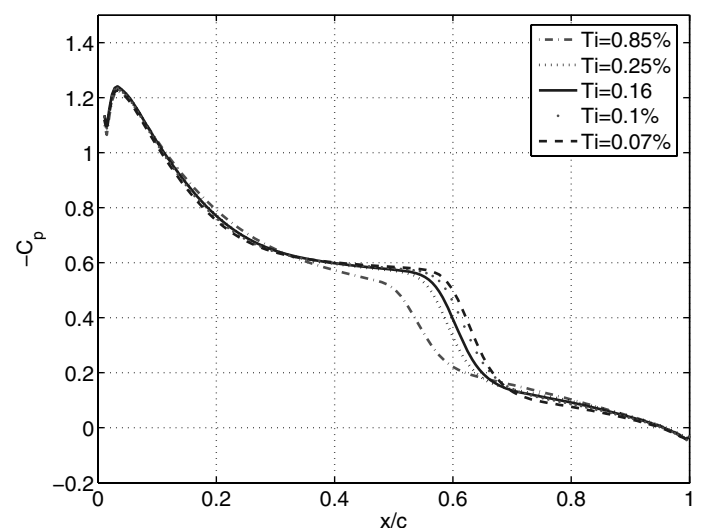

Fig. 9 Pressure coefficient on the suction surface at $\alpha=4 \mathrm{deg}$ at different turbulence levels.

\section{Effect of Reynolds Number}

For a low Reynolds number airfoil, the chord Reynolds number plays a predominated role in the overall performance. As the Reynolds number increases, the Reynolds number based on the momentum thickness increases accordingly. Between the separation position and the transition position, as shown in Fig. 12a, both $H$ and $R e_{\theta}$ increase with the Reynolds number. From Eq. ( $\overline{9}$ ), we conclude that the growth rate of the amplification factor before separation increases with the Reynolds number, contributing to earlier transition at a higher Reynolds number. Meanwhile, the viscosity changes the effective shape of the airfoil. Among the studied four cases, as shown in Fig. 12b, the effective airfoil shape at $R e=4 \times$ $10^{4}$ has the largest camber. This partially explains why the largest lift coefficient is obtained at $R e=4 \times 10^{4}$ (Fig. 12c). The camber decreases significantly when the Reynolds number increases from $4 \times 10^{4}$ to $6 \times 10^{4}$, but does not show considerable change when the Reynolds number increases further. Therefore, we do not observe distinct increase in the lift coefficient, even though the LSB length is shorter at a higher Reynolds number. We can conclude from Fig. 12d that the larger lift-to-drag ratio is mainly due to the reduction of friction drag at a higher Reynolds number. The form drag due to the pressure does not vary as much as the friction drag as the Reynolds number increases. In the application of MAVs, the enhanced lift-todrag ratio will favor the power efficiency [5] , which is a function of lift-to-drag ratio and increases with the ratio.

Carmichael [63] pointed out that roughly the distance from separation to reattachment can be expressed as a Reynolds number based on the bubble length of about 50,000. A minimum Reynolds number of 70,000 is generally accepted for flow reattachment, based on observation [60]. In our cases, the flow can reattach at a Reynolds number as low as $4 \times 10^{4}$. This suggests that the transition, separation, and reattachment characteristics are highly dependent on the geometry and angles of attack.
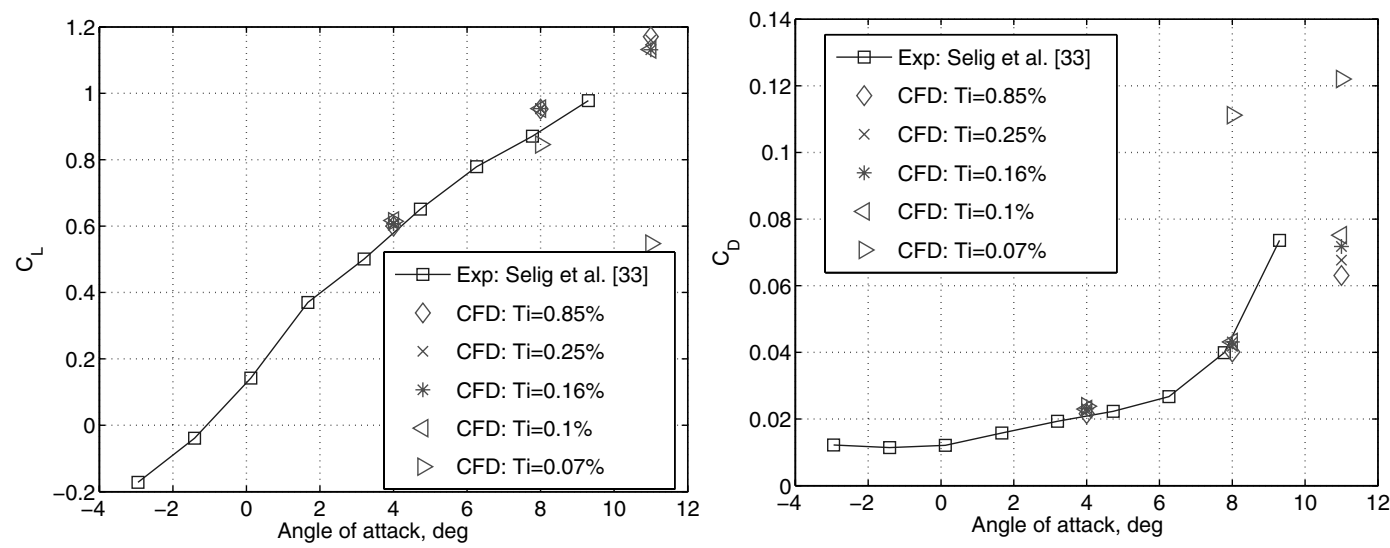

Fig. 8 Lift and drag coefficients vs angle of attack at different turbulence levels. 

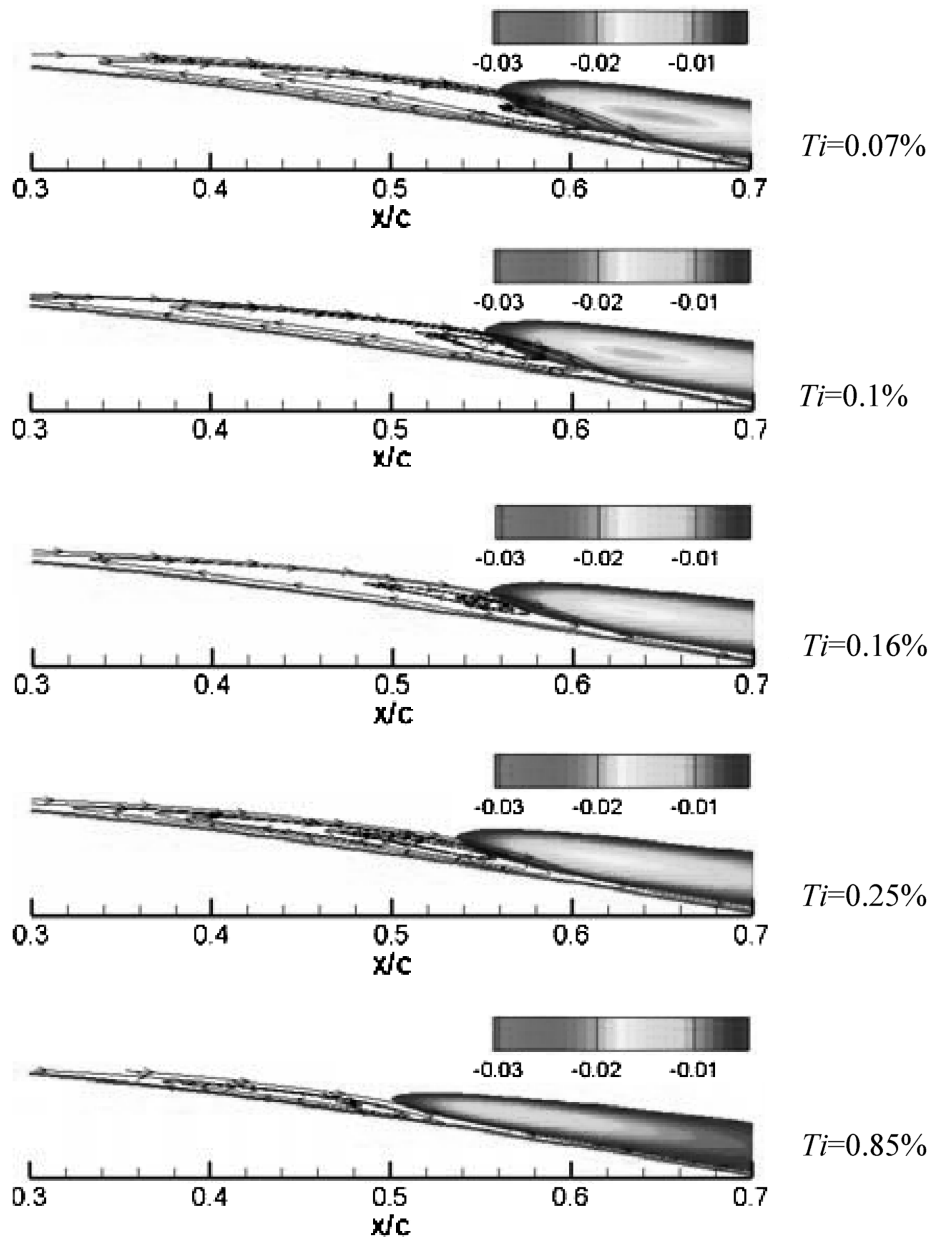

Fig. 10 Streamlines and normalized shear stress contours at $\alpha=\mathbf{4} \mathrm{deg}$ for different turbulence levels.

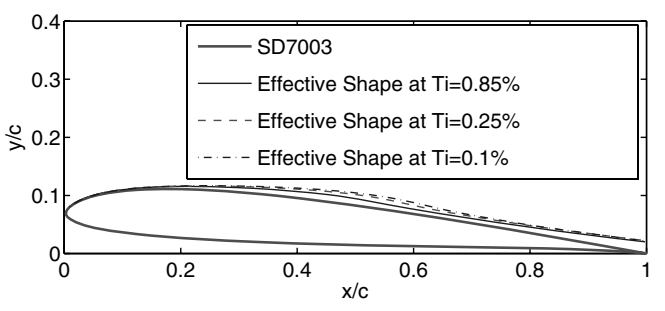

Fig. 11 Effective airfoil shape at different turbulence levels.

\section{Effect of Gust}

The real operating condition for MAVs is quite different from the ideally quiet wind/water tunnel setup. In real flight, MAVs may have to operate in a gusty environment. The effect of unsteady flow on transition was studied by Obremski and Fejer [64]. They experimented with a flat-plate airflow in which the freestream velocity varies sinusoidally with a mean:

$$
U=U_{0}\left(1+N_{A} \sin \omega_{g} t\right)
$$

where $N_{A}$ is the gust fluctuation amplitude ratio and $\omega_{g}$ is the gust frequency. They found that the transition Reynolds number is affected by the freestream oscillation when the so-called nonsteady Reynolds number, $R e_{\mathrm{ns}}=N_{A} U_{0}^{2} / \omega_{g} v$, is above a critical point of about 26,000. Below the critical value, the unsteady freestream exhibits little impact on the transition process. Obremski and Morkovin [65] observed that in both high and low $R e_{\mathrm{ns}}$ ranges, the initial turbulent bursts are preceded in space and time by a disturbance wave packet. By applying a quasi-steady stability model, they concluded that in the high $R e_{\mathrm{ns}}$ range, the wave packet is amplified rapidly and bursts into turbulence, whereas in the low range, the wave packet bursts into turbulence at a much higher Reynolds number. Guided by their study, we investigate the influence of freestream oscillations on the transition for separated flows. First, we set $N_{A}=0.33$ and $\omega_{g}=0.3$, resulting in a nonsteady Reynolds number of 99,000 . The frequency $\omega_{g}$ is kept well below the range of the expected unstable TS wave frequency, which is around $10 \mathrm{~Hz}$.

Figure 13 shows the lift coefficient and lift-to-drag ratio during one selected gust cycle. Clearly, under gust condition, the aerodynamic coefficients display the hysteresis phenomena. For example, when the flow accelerates, the lift coefficient does not immediately reach its corresponding steady-state value. Compared with steady freestream, the gust leads to a higher lift coefficient at the low-velocity end and lower lift coefficient at the high-velocity end. The lift-to-drag ratio variation during one cycle is substantial. For example, at the instantaneous Reynolds number of $6 \times 10^{4}$, the liftto-drag ratio is around 26 when the freestream is steady; for gust flow, the lift-to-drag ratio is 20 when the flow accelerates, and it elevates to 38 when the flow decelerates.

Along with the variations in lift and drag coefficients, the transition position is also affected by the gust. As shown in Fig. 14, the transition position moves toward the leading edge when the flow is accelerating and moves toward the trailing edge when the flow is decelerating. During the accelerating stage, as the instantaneous Reynolds number is increasing, the flow experiences early transition. In our simulation, we link the transition point to the computational grid point and we do not differentiate any position in between, which makes the plot in Fig. 14 discontinuous; a refined grid will help smooth out the discontinuity.

We also perform a test with a higher gust frequency of $\omega_{g}=1.5$, resulting in a nonsteady Reynolds number of 19,800 , which is lower than the critical value. Contradicting the observation of Obremski 


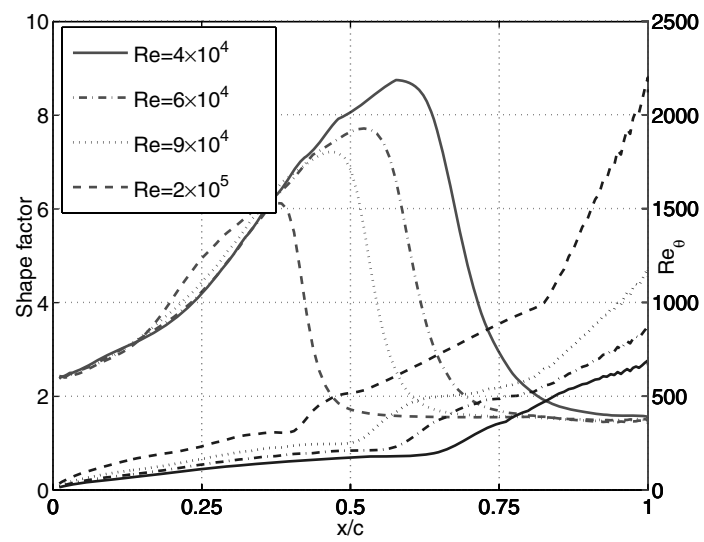

a)

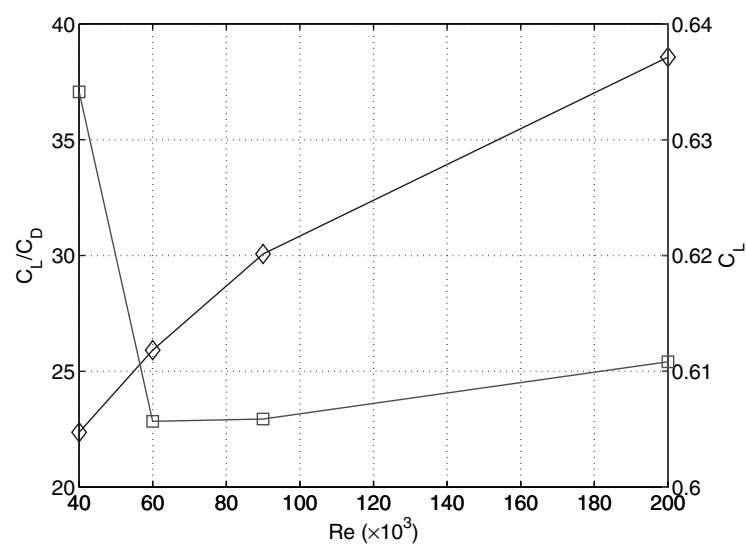

c)

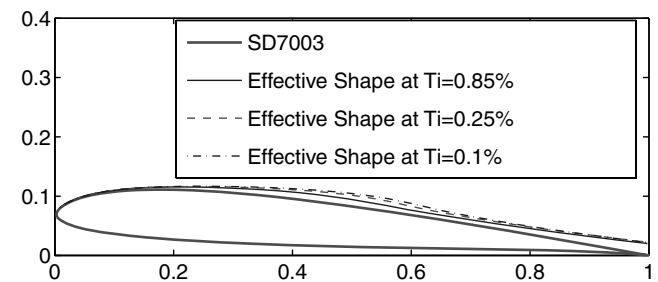

b)

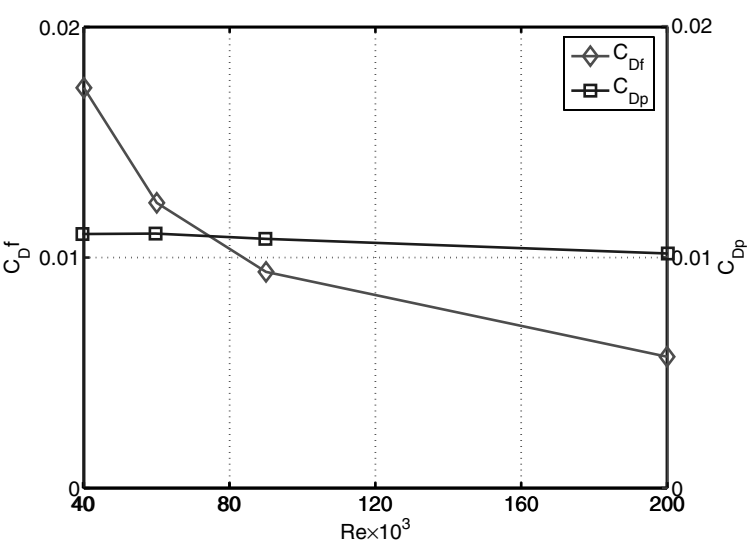

d)

Fig. 12 Reynolds number effect on the LSB profile and aerodynamic performance at $\alpha=4 \mathrm{deg}$ : a) shape factor and momentum thickness based Reynolds number, b) effective airfoil shape, c) lift-to-drag ratio, and d) drag coefficient.

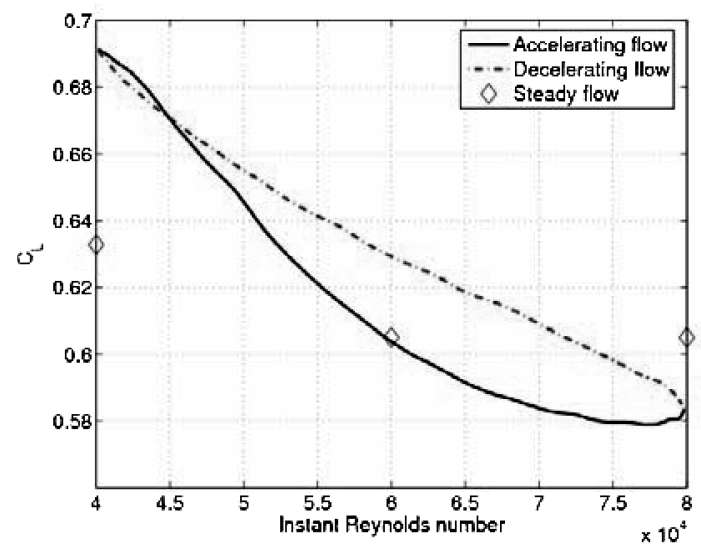

Fig. 13 Aerodynamic coefficient in gusty environment during one cycle for $R e_{\mathrm{ns}}=99,000$, showing the hysteresis phenomenon; lift coefficient (left) and lift-to-drag ratio (right).

and Morkovin [65], our simulation shows that the transition position also varies with the instant Reynolds number (Fig. 14). It should be noted that Obremski and Morkovin drew their conclusions based on experiments over a flat plate at a much higher Reynolds number of $10^{6}$. In their test, the flow is the Blasius flow and experiences natural transition. In our test, the separated flow amplifies the unstable TS wave in such a great rate that it leads to faster transition to turbulence, typical of the bypass transition scenario.

Comparison of the transition position at the two different nonsteady Reynolds numbers reveals that the flow experiences transition for the whole oscillation cycle at low gust frequency, whereas the flow becomes laminar at the early accelerating state and remains such until the instant Reynolds number reaches around
$7 \times 10^{4}$ at high gust frequency. We surmise that during the decelerating stage, the transition position moves toward the trailing edge due to the reduced Reynolds number. At a higher nonsteady Reynolds number (i.e., lower frequency), the deceleration has less impact on the transition and the LSB can sustain itself. However, at a lower nonsteady Reynolds number (i.e., higher frequency), the deceleration has more impact on the transition, and the LSB cannot adjust itself with the high rate change to maintain the closed bubble and the LSB bursts. A closed LSB forms only when the Reynolds number reaches $7 \times 10^{4}$. To better appreciate this phenomenon, we plot the phase and shape factor during one cycle in Fig. 15.

Another interesting observation at $R e_{\mathrm{ns}}=19,800$ is the drag coefficient, shown in Fig. 16. During the decelerating stage, the gusty

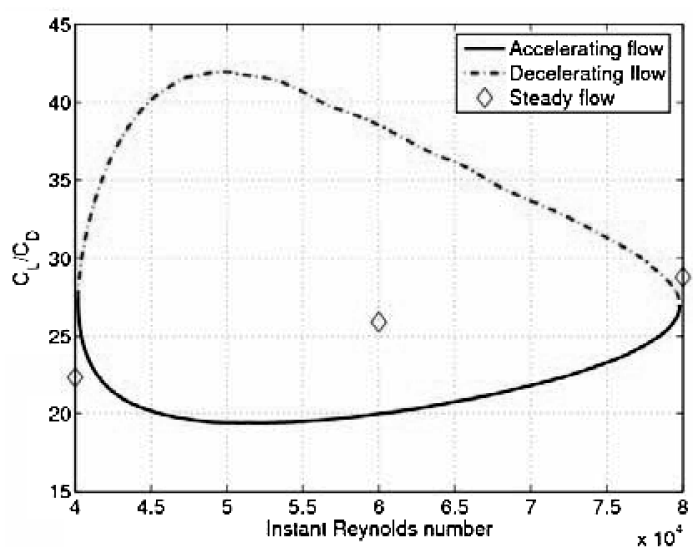



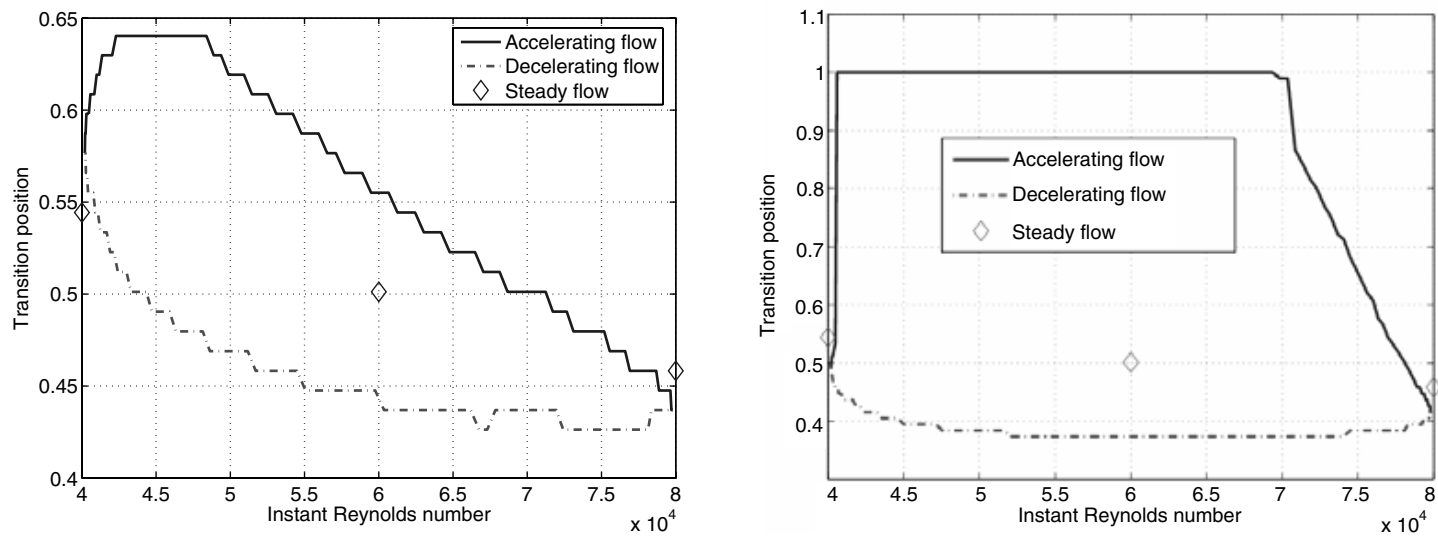

Fig. 14 Transition position during one cycle $R e_{\mathrm{ns}}=99,000$ (left) and $R e_{\mathrm{ns}}=19,800$ (right).
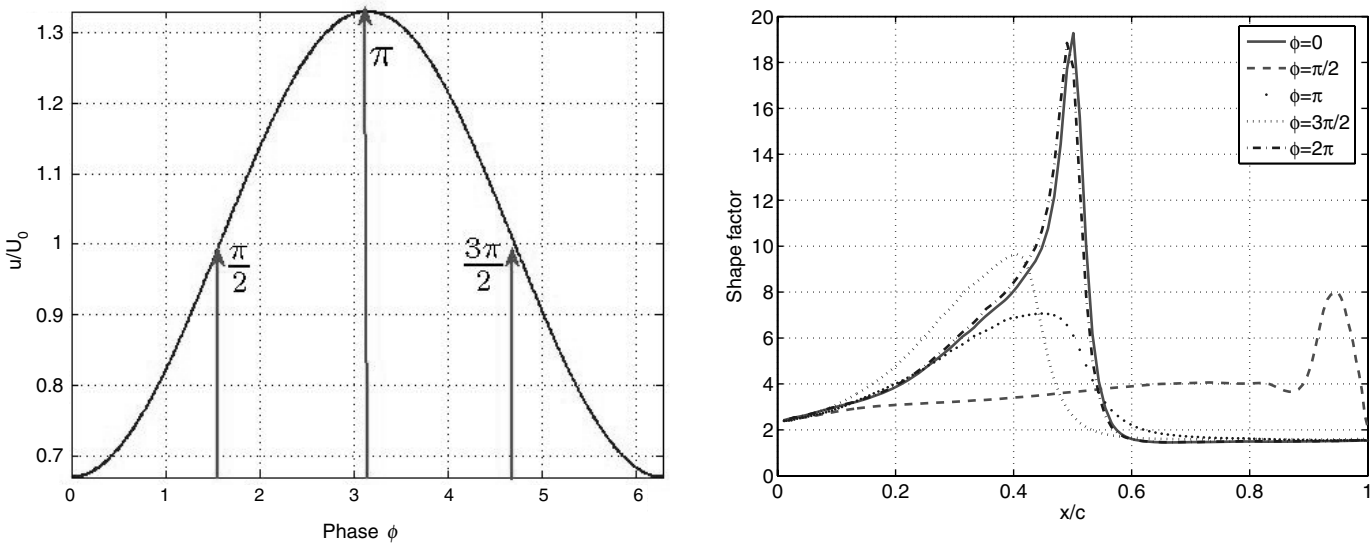

Fig. 15 Phase (left) and shape factor (right) during one cycle $R e_{\mathrm{ns}}=19,800$.

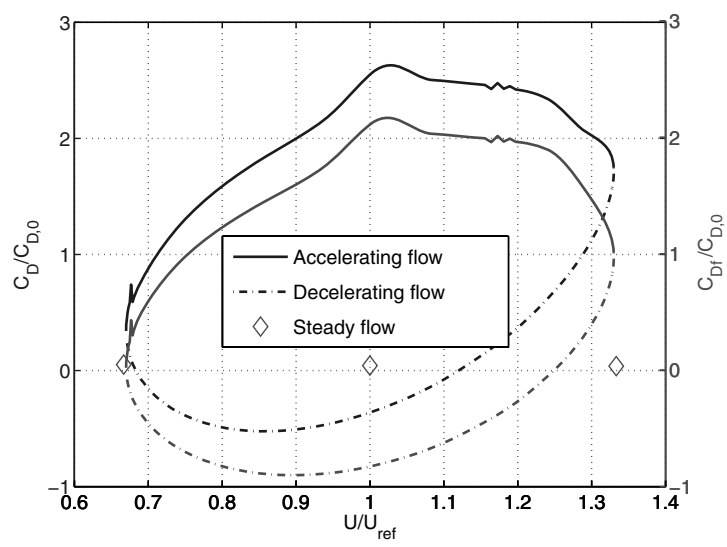

Fig. 16 Drag coefficient in gusty environment during one cycle for $R e_{\mathrm{ns}}=19,800$.

flow produces thrust. Analysis shows that the thrust is due to the friction force.

The $e^{N}$ method is based on the assumption of a steady boundary layer. Hence, its application to unsteady flow raises questions because during the unsteady change of the boundary layer, both the frequency and the amplification rates of the unstable modes change. However, under certain circumstances, the $\mathrm{e}^{N}$ method can give reasonably good prediction, even for unsteady flow. The key is to look at the two time scales involved in the specific problem. One is the time that unstable modes need to travel downstream while being amplified, which is on the order of $T_{b}=\delta x / U_{g}$, where $\delta x$ is the size of the region with amplification and $U_{g}$ is the group velocity that may be approximated by the freestream mean velocity $U_{0}$. The other is the characteristic time of flow state change $0.5 T_{g}$, where $T_{g}$ is the motion period of the freestream velocity. If $T_{b}$ is much smaller than $T_{g}$, then the quasi-steady transition model can resolve the unsteady physical effect and the use of the $e^{N}$ method is justified. In our tested cases, the motion period of the freestream velocity $T_{g}$, which is $20 \pi / 3$ and $4 \pi / 3$, respectively, is much larger than $T_{b}$, which is close to 0.02 . Therefore, we can still use the $e^{N}$ method.

\section{Flexible-Wing Simulation}

In the following, we examine the impact of flexible surface on the transition process. We cover a portion of the upper surface of the SD7003 airfoil with latex membrane, extending from 33 to $52 \%$ of the chord from the leading edge (Fig. 17). No pretension is applied to the membrane. The membrane has a uniform thickness of $0.2 \mathrm{~mm}$ and a density of $1200 \mathrm{~kg} / \mathrm{m}^{3}$. The two parameters governing the membrane property, as shown in Eq. (16), take the values of $c_{1}=$ $5.0 \times 10^{5} \mathrm{~Pa}$ and $c_{2}=0.785 c_{1}$. The freestream velocity is equal to $0.3 \mathrm{~m} / \mathrm{s}$, the airfoil chord length is $20 \mathrm{~cm}$, and the angle of attack is $4 \mathrm{deg}$. With these parameters, the time step for the CFD solver is set to $2 \times 10^{-3} \mathrm{~s}$ and the time step of the structural solver is $1 \times 10^{-5} \mathrm{~s}$.

It is observed that the flexible surface changes its shape over time when the flow passes by (Fig. 17). Analysis reveals that the transverse velocity magnitude can reach as high as $10 \%$ of the freestream speed. Because of the vibration, energy is transferred from the flexible surface to the flow and the separated flow is energized. Compared with rigid-airfoil simulation, the separation and transition positions on the flexible airfoil show significant variations, with a standard variation of $6 \%$ of its mean. Figure 18 shows the time history of the lift coefficient. Even though the timeaveraged lift coefficient of the flexible airfoil is equal to the lift coefficient of the corresponding rigid airfoil, the instantaneous lift coefficient displays a large variation over its mean. The timeaveraged drag coefficient also matches that of the rigid wing. These observations are consistent with our previous findings based on 


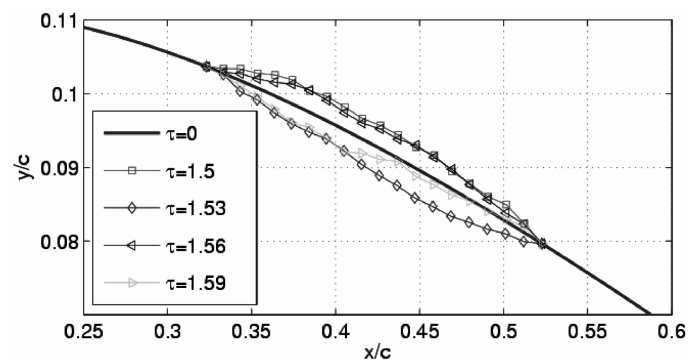

Fig. 17 Membrane airfoil shapes at different time instants.

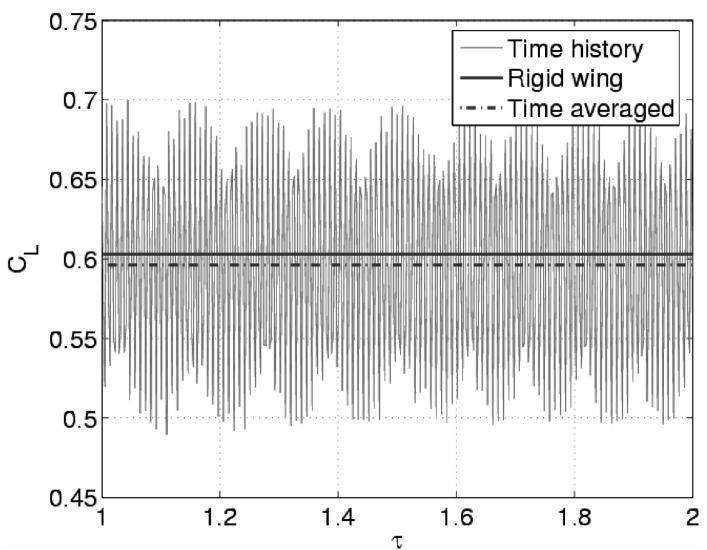

Fig. 18 Time history of lift coefficient for membrane wing showing both high- and low-frequency oscillation.

three-dimensional MAV wing simulations without transitional flow models [8]. Using discrete Fourier transformation analysis, we find that there is a dominated vibration frequency $(167 \mathrm{~Hz})$ associated with the membrane airfoil vibration (Fig. 19). Given the airfoil chord length $(0.2 \mathrm{~m})$ and freestream speed $(0.3 \mathrm{~m} / \mathrm{s})$, this high-vibration frequency is unlikely to affect the vehicle stability. Further investigation of Fig. 18 reveals that in addition to the high-frequency behavior, there is a low-frequency cycle in the lift coefficient history. This cycle, with a frequency of about $14 \mathrm{~Hz}$, seems to be associated with the periodic vortex shedding (Fig. 20).

\section{Conclusions}

We coupled a Navier-Stokes equation solver with a transition model and a Reynolds-averaged two-equation closure to study the low Reynolds number flow characterized with laminar separation and transition. The transition model is based on the $e^{N}$ method, derived from the linear stability analysis and Orr-Sommerfeld equations. An intermittency distribution function suitable for low Reynolds number transitional flow is proposed and tested. With the

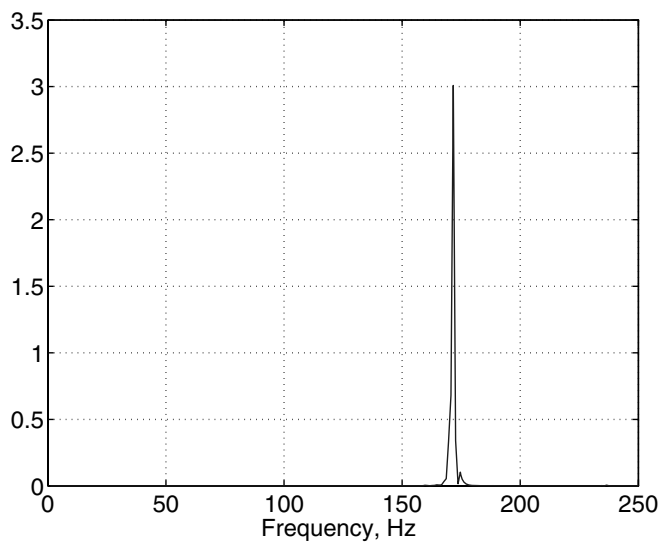

Fig. 19 Power spectrum of the Fourier transformation of the lift force.
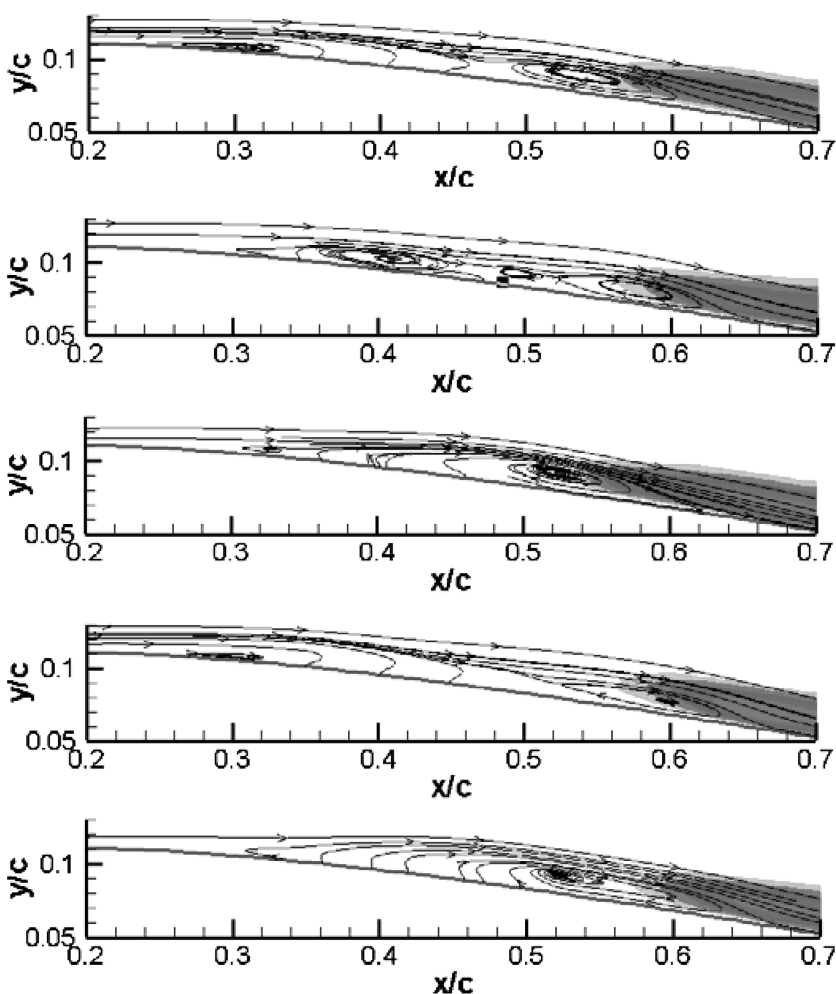

Fig. 20 Flow structure over the membrane wing and the associated vortex shedding at $\alpha=4 \mathrm{deg}$ and $R e=60,000$; from top to bottom, time instant $\tau=1.5,1.506,1.512,1.515$, and 1.521 .

developed capability, we studied the impacts of different factors on transition process and on the airfoil performance. We observed the following:

1) Good agreement between our prediction and experimental measurements regarding the transition location and overall flow structures is observed.

2) As expected, both the separation position and transition position move upstream with increasing angle of attack. The stronger adverse pressure gradient amplifies the unstable TS wave and expedites the transition. Before stall, the laminar separation bubble becomes shorter and thinner with the increase of angle of attack.

3) Increased freestream turbulence intensity prompts the transition, resulting in a shorter and thinner separation bubble. Increased turbulence intensity also leads to higher pressure and velocity peak.

4) Inspecting the flow characteristics between $R e=4 \times 10^{4}$ and $2 \times 10^{5}$, one can clearly observe that the actual value of the Reynolds number plays a significant role in the overall airfoil performance. It has similar impacts as the turbulence intensity. For the studied airfoil, though increasing the Reynolds number can shorten the laminar separation bubble, it does not necessarily increase the lift or decrease the drag.

5) The transition position is affected by the gust. When the flow accelerates/decelerates, the transition position moves upstream/ downstream due to the increasing/decreasing Reynolds number. In the meantime, the lift coefficient demonstrates hysteresis corresponding to the acceleration and deceleration process.

6) For a flexible wing, self-excited vibration at around $167 \mathrm{~Hz}$ is exhibited. During the vibration process, energy is transferred from the flexible surface to the fluid flow, causing the change of flow pattern. Both the separation and transition positions are affected by the vibration. However, at $\alpha=4 \mathrm{deg}$, the time-averaged lift and drag coefficients are close to those of the steady-state flow around the rigid airfoil. Of course, the frequency of gust, the position of the flexible surface, and the membrane property are critical factors in the transition process. These aspects should be further investigated.

7) The employed transition model is based on linear stability analysis and is designed for steady-state flows. It is based on the 
assumptions that the initial disturbance is small and the boundary layer is thin. Good agreement is achieved in test cases for a broad range of conditions; nevertheless, further tests are required to assess the applicability of the model for general low Reynolds number aerodynamics application.

\section{Acknowledgments}

The present work was supported in part by the U.S. Air Force. The authors have benefited from the discussion with Michael $\mathrm{Ol}$ of the U.S. Air Force Research Laboratory, Rolf Radespiel of the Technical University of Braunschweig, and Dun Liu of the Chung-Shan Institute of Technology.

\section{References}

[1] Grasmeyer, J. M., and Keennon, M. T., "Development of the Black Widow Micro Air Vehicle," AIAA Paper No. 2001-0127, 2001.

[2] Ifju, P. G., Jenkins, A. D., Ettingers, S., Lian, Y., and Shyy, W., "Flexible-Wing-Based Micro Air Vehicles," AIAA Paper 2002-0705, 2002

[3] Jones, K. D., Bradshaw, C. J., Papadopoulos, J., and Platzer, M. F., "Improved Performance and Control of Flapping-Wing Propelled Micro Air Vehicles," AIAA Paper 2004-0399, 2004.

[4] Jones, K. D., and Platzer, M. F., "Experimental Investigation of the Aerodynamic Characteristics of Flapping-Wing Micro Air Vehicles," AIAA Paper 2003-0418, 2003.

[5] Shyy, W., Berg, M., and Ljungqvist, D., "Flapping and Flexible Wings for Biological and MicroVehicles," Progress in Aerospace Sciences, Vol. 35, No. 5, 1999, pp. 455-506.

[6] Lian, Y., Shyy, W., Viieru, D., and Zhang, B. N., "Membrane Wing Aerodynamics for Micro Air Vehicles," Progress in Aerospace Sciences, Vol. 39, Nos. 6-7, 2003, pp. 425-465.

[7] Waszak, R. M., Jenkins, N. L., and Ifju, P., "Stability and Control Properties of an Aeroelastic Fixed Wing Micro Aerial Vehicle," AIAA Atmospheric Flight Mechanics Conference and Exhibit, Montreal, Canada, AIAA Paper 2001-4005, 2001.

[8] Lian, Y., and Shyy, W., "Numerical Simulations of Membrane Wing Aerodynamics for Micro Air Vehicle Applications," Journal of Aircraft, Vol. 42, No. 4, 2005, pp. 865-873.

[9] Jones, B. M., "Stalling," Journal of the Royal Aeronautical Society, Vol. 38, 1938, pp. 747-770

[10] Young, A. D., and Horton, H. P., "Some Results of Investigation of Separation Bubbles," AGARD Conference Proceedings, Vol. 4, AGARD, London, 1966, pp. 779-811.

[11] Tani, I., "Low Speed Flows Involving Bubble Separations," Progress in Aeronautical Sciences, Pergamon, New York, 1964, pp. 70-103.

[12] Smith, A. M. O., and Gamberoni, N., "Transition, Pressure Gradient, and Stability Theory," Douglas Aircraft, Rept. ES-26388, 1956.

[13] Van Ingen, J. L., "A Suggested Semi-Empirical Method for the Calculation of the Boundary Layer Transition Region," Inst. of Technology, Department of Aeronautics and Engineering, Rept. VTH74, Delft, Holland, The Netherlands, 1956.

[14] Roberts, W. B., "Calculation of Laminar Separation Bubbles and Their Effect on Airfoil Performance," AIAA Journal, Vol. 18, No. 1, 1980, pp. 25-31.

[15] Davis, R. L., Carter, J. E., and Reshotko, E., "Analysis of Transitional Separation Bubbles on Infinite Swept Wings," AIAA Journal, Vol. 25. No. 3, 1987, pp. 421-428.

[16] Volino, R. J., and Bohl, D. G., "Separated Flow Transition Mechanism and Prediction with High and Low Freestream Turbulence under Low Pressure Turbine Conditions," American Society of Mechanical Engineers Paper No. GT2004-53360, 2004

[17] Mayle, R. E., "The Role of Laminar-Turbulent Transition in Gas Turbine Engine," Journal of Turbomachinery, Vol. 113, 1991, pp. 509537.

[18] Praisner, T. J., and Clark, J. P., "Predicting Transition in Turbomachinery, Part I-A Review and New Model Development," American Society of Mechanical Engineers Paper No. GT2004-54108, 2004.

[19] Roberts, S. K., and Yaras, M. I., "Effects of Surface Roughness Geometry on Separation Bubble Transition," American Society of Mechanical Engineers Paper No. GT2005-68664, 2005.

[20] Wazzan, A. R., Gazley, C., Jr., and Smith, A. M. O., "TollmienSchlichting Waves and Transition," Progress in Aerospace Sciences, Vol. 18, No. 2, 1979, pp. 351-392.

[21] He, X., Senocak, I., Shyy, W., Gangadharan, S. N., and Thakur, S.,
"Evaluation of Laminar-Turbulent Transition and Equilibrium Near Wall Turbulence Models," Numerical Heat Transfer, Part A, Applications, Vol. 37, No. 2, 2000, pp. 101-112.

[22] Cebeci, T., "Essential Ingredients of a Method for Low ReynoldsNumber Airfoils," AIAA Journal, Vol. 27, No. 12, 1988, pp. 16801688.

[23] Drela, M., and Giles, M. B., "Viscous-Inviscid Analysis of Transonic and Low Reynolds Number Airfoils," AIAA Journal, Vol. 23, No. 10 1987, pp. 1347-1355.

[24] Holloway, D. S., Walters, D. K., and Leylek, J. H., "Prediction of Unsteady, Separated Boundary Layer over a Blunt Body for Laminar, Turbulent, and Transitional Flow," International Journal for Numerical Methods in Fluids, Vol. 45, No. 12, 2004, pp. 1291-1315.

[25] Edwards, J. R., Roy, C. J., Blottner, F. G., and Hassan, H. A., "Development of a One-Equation Transition/Turbulence Model," AIAA Journal, Vol. 39, No. 9, 2001, pp. 1691-1698.

[26] Warren, E. S., and Hassan, H. A., "Transition Closure Model for Predicting Transition Onset," Journal of Aircraft, Vol. 35, No. 5, 1998 , pp. 769-775.

[27] Spalart, P. R., and Allmaras, S. R., "A One-Equation Turbulence Mode for Aerodynamic Flow," La Recherche Aerospatiale : Bulletin Bimestriel de l'Office National d'Etudes et de Recherches Aerospatiales, Vol. 1, 1994, pp. 5-21.

[28] Wilcox, D. C., "Simulation of Transition with a Two-Equation Turbulence Model," AIAA Journal, Vol. 32, No. 2, 1994, pp. 247-255.

[29] Steelant, J., and Dick, E., "Modeling of Bypass Transition with Conditioned Navier-Stokes Equations Coupled to an Intermittency Transport Equation," International Journal for Numerical Methods in Fluids, Vol. 23, No. 3, 1996, pp. 193-220.

[30] Suzen, Y. B., and Huang, P. G., "Modeling of Flow Transition Using an Intermittency Transport Equation," Journal of Fluids Engineering, Vol. 122, No. 2, 2000, pp. 273-284.

[31] Suzen, Y. B., Xiong, G., and Huang, P. G., "Predictions of Transitional Flows in Low-Pressure Turbines Using Intermittency Transport Equation," AIAA Journal, Vol. 40, No. 2, 2002, pp. 254-266.

[32] Zheng, X., Liu, C., Liu, F., and Yang, C., "Turbulence Transition Simulation Using the K-w Model," International Journal for Numerical Methods in Engineering, Vol. 42, No. 5, 1998, pp. 907-926.

[33] Selig, M. S., Guglielmo, J. J., Broeren, A. P., and Giguere, P., Summary of Low Speed Airfoil Data, Vol. 1, Soartech Aero, Virginia Beach, VA, 1995.

[34] Radespiel, R., Graage, K., and Brodersen, O., "Transition Predictions Using Reynolds-Averaged Navier-Stokes and Linear Stability Analysis Methods," AIAA Paper 91-1641, June 1991.

[35] Stock, H. W., and Haase, W., "A Feasibility Study of $\mathrm{e}^{N}$ Transition Prediction in Navier-Stokes Methods for Airfoils," AIAA Journal, Vol. 37, No. 10, 1999, pp. 1187-1196.

[36] Yuan, W., Khalid, M., Windte, J., Scholz, U., and Radespiel, R., "An Investigation of low Reynolds-Number Flows Past Airfoils," 23rd AIAA Applied Aerodynamics Conference, Toronto, AIAA Paper 20054607, 2005.

[37] Arnal, D., Casalis, G., and Juillen, J. C., "A Survey of the Transition Prediction Methods: from Analytical Criteria to PSE and DNS," in Turbulence and Transition Modeling, edited by M. Hallback, ERCOFTAC Series, Vol. 2, Kluwer Academic, Dordrecht, Holland, The Netherlands, 1996, pp. 3-14.

[38] Strelets, M., "Detached Eddy Simulation of Massively Separated Flows," AIAA Paper 2001-0879, 2001

[39] Yang, Z., and Voke, P., "Large Eddy Simulation of Boundary-Layer Separation and Transition at a Change of Surface Curvature," Journal of Fluid Mechanics, Vol. 439, 2001, pp. 305-333.

[40] Ol, M., McAuliffe, B. R., Hanff, E. S., Scholz, U., and Kaehler, C., "Comparison of Laminar Separation Bubble Measurements on a Low Reynolds Number Airfoil in Three Facilities," 23rd AIAA Applied Aerodynamics Conference, Toronto, AIAA Paper 2005-5149, 2005.

[41] Hanff, E. S., "PIV Application in Advanced Low Reynolds Number Facility," IEEE Aerospace and Electronic Systems Magazine, Vol. 40, pp. 310-319, 2004.

[42] Radespiel, R., Windte, J., and Scholz, U.,"Numerical and Experimental Flow Analysis of Moving Airfoil with Laminar Separation Bubbles," AIAA Paper 2006-0501, 2006.

[43] Patankar, S. V., and Spalding, D. B., "A Calculation Procedure for Heat, Mass and Momentum Transfer in Three-Dimensional Parabolic Flows," International Journal of Heat and Mass Transfer, Vol. 15, No. 10, 1972, pp. 1787-1806.

[44] Shyy, W., Computational Modeling for Fluid Flow and Interfacial Transport, Elsevier, Amsterdam, The Netherlands, 1994; revised printing 1997.

[45] Wilcox, D., Turbulence Modeling for CFD, 2nd ed., DCW Industries, 
Inc., La Canada, CA, 2000.

[46] Gleyzes, C., Cousteix, Jr., and Bonnet, J. L., "Theoretical and Experimental Study of Low Reynolds Number Transitional Separation Bubbles," Proceedings of the Conference on Low Reynolds Number Airfoil Aerodynamics, UNDAS-CP-77B123, Univ. of Notre Dame, Notre Dame, IN, 1985, pp. 137-152.

[47] Rist, U., "Zur Instabilität und Transition in Laminaren Ablöseblasen," Habilitation Dissertation, Univ. Stuttgart, Stuttgart, Germany, 1999.

[48] Watmuff, J. H., "Evolution of a Wave Packet into Vortex Loops in a Laminar Separation Bubble," Journal of Fluid Mechanics, Vol. 397, 1999, pp. 119-169.

[49] Dhawan, S., and Narasimha, R., "Some Properties of Boundary Layer During the Transition from Laminar to Turbulent Flow Motion," Journal of Fluid Mechanics, Vol. 3, 1958, pp. 418-436.

[50] Chen, K. K., and Thyson, N. A., "Extension of Emmons' Spot Theory to Flows on Blunt Bodies," AIAA Journal, Vol. 9, No. 5, 1971, pp. 821825.

[51] Mack, L. M., "Transition Prediction and Linear Stability Theory," AGARD Conference Proceedings, CP-224, AGARD, London, 1977, pp. 1-1-1-22.

[52] Henkes, R. R. W. M., and van Ingen, J. L. (eds.), "Some Introductory Remarks on Transition Prediction Methods Based on Linear Stability Theory," Transitional Boundary Layers in Aeronautics, NorthHolland, Amsterdam, Holland, The Netherlands, 1996, pp. 209-224.

[53] Lian, Y., Shyy, W., Ifju, P., and Verron, E., "A Membrane Wing Model for Micro Air Vehicles," AIAA Journal, Vol. 41, No. 12, 2003, pp. 2492-2494; also AIAA Paper 2002-2972.

[54] Green, A. E., and Adkins, J. E., Large Elastic Deformations, Clarendon, Oxford, England, U.K., 1960.

[55] Mooney, M., "A Theory of Large Elastic Deformation," Journal of Applied Physics, Vol. 11, 1940, pp. 582-592.
[56] Bathe, K. J., Finite Element Procedures, Prentice-Hall, Upper Saddle River, NJ, 1996.

[57] Lian, Y., Steen, J., Trygg-Wilander, M., and Shyy, W., "Low Reynolds Number Turbulent Flows Around a Dynamically Shaped Airfoil," Computers and Fluids, Vol. 32, No. 3, 2003, pp. 287-303; also AIAA Paper 2001-2723.

[58] Visbal, M. R., and Gaitonde, D. V., "On the Use of Higher-Order FiniteDifference Schemes on Curvilinear and Deforming Meshes," Journal of Computational Physics, Vol. 181, No. 1, 2002, pp. 155-185.

[59] Thomas, P. D., and Lombard, C. K., "Geometric Conservation Law and its Application to Flow Computations on Moving Grids," AIAA Journal, Vol. 17, No. 10, 1979, pp. 1030-1037.

[60] Lissaman, P. B. S., "Low Reynolds-Number Airfoils," Annual Review of Fluid Mechanics, Vol. 15, 1983, pp. 223-239.

[61] Menter, F. R., "Two-Equation Eddy-Viscosity Transport Turbulence Model for Engineering Applications," AIAA Journal, Vol. 32, No. 8, 1994, pp. 1598-1605.

[62] O'Meara, M. M., and Mueller, T. J., "Laminar Separation Bubble Characteristics on an Airfoil at Low Reynolds Numbers," AIAA Journal, Vol. 25, No. 8, 1987, pp. 1033-1041.

[63] Carmichael, B. H., "Low Reynolds Number Airfoil Survey," NASA CR 165803, 1981.

[64] Obremski, H. J., and Fejer, A. A., "Transition in Oscillating Boundary Layer Flow," Journal of Fluid Mechanics, Vol. 29, 1967, pp. 93-111.

[65] Obremski, H. J., and Morkovin, M. V., "Application of a Quasi-Steady Stability Model to Periodic Boundary Layer Flows," AIAA Journal, Vol. 7, No. 7, 1969, pp. 1298-1301. 